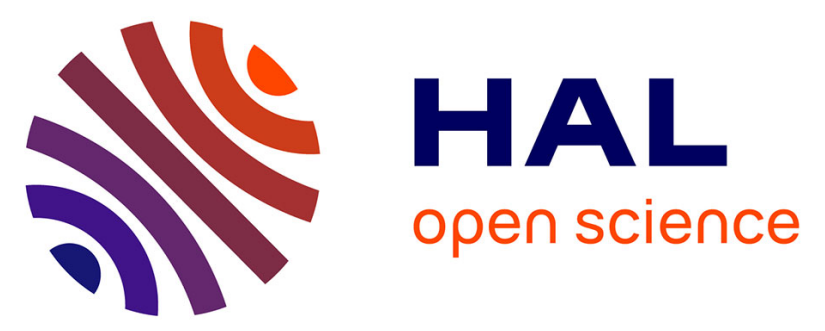

\title{
Nyctemeral variations of magnesium intake in the calcitic layer of a Chilean mollusk shell (Concholepas concholepas, Gastropoda)
}

Claire E. Lazareth, Nury Guzmán, Franck Poitrasson, Frédéric Candaudap, Luc Ortlieb

\section{To cite this version:}

Claire E. Lazareth, Nury Guzmán, Franck Poitrasson, Frédéric Candaudap, Luc Ortlieb. Nyctemeral variations of magnesium intake in the calcitic layer of a Chilean mollusk shell (Concholepas concholepas, Gastropoda). Geochimica et Cosmochimica Acta, 2007, 71 (22), pp.5369 - 5383. 10.1016/j.gca.2007.07.031 . ird-01697771

\section{HAL Id: ird-01697771 \\ https://hal.ird.fr/ird-01697771}

Submitted on 31 Jan 2018

HAL is a multi-disciplinary open access archive for the deposit and dissemination of scientific research documents, whether they are published or not. The documents may come from teaching and research institutions in France or abroad, or from public or private research centers.
L'archive ouverte pluridisciplinaire HAL, est destinée au dépôt et à la diffusion de documents scientifiques de niveau recherche, publiés ou non, émanant des établissements d'enseignement et de recherche français ou étrangers, des laboratoires publics ou privés. 


\title{
Nyctemeral variations of magnesium intake in the calcitic layer of a Chilean mollusk shell (Concholepas concholepas, Gastropoda)
}

\author{
Claire E. Lazareth ${ }^{\mathrm{a}, *}$, Nury Guzman ${ }^{\mathrm{a}}$, Franck Poitrasson ${ }^{\mathrm{b}}$, \\ Frederic Candaudap ${ }^{b}$, Luc Ortlieb ${ }^{a}$ \\ a IRD, PALEOTROPIQUE, 32 avenue Henri Varagnat, Bondy F-93143, France \\ b Laboratoire d'étude des Mécanismes de Transfert en Géologie Centre National de la Recherche Scientifique-UPS-IRD, \\ 14-16, avenue Edouard Belin, Toulouse F-31400, France
}

\begin{abstract}
Mollusk shells are increasingly used as records of past environmental conditions, particularly for sea-surface temperature (SST) reconstructions. Many recent studies tackled SST (and/or sea-surface salinity) tracers through variations in the elementary $(\mathrm{Mg}$ and $\mathrm{Sr})$ or stable isotope $\left(\delta^{18} \mathrm{O}\right)$ composition within mollusk shells. But such attempts, which sometimes include calibration studies on modern specimens, are not always conclusive. We present here a series of $\mathrm{Mg}$ and $\mathrm{Sr}$ analyses in the calcitic layer of Concholepas concholepas(Muricidae, Gastropoda) with a very high time-resolution on a time window covering about 1 and a half month of shell formation, performed by Laser Ablation Inductively-Coupled Plasma Mass Spectrometry (LA-ICP-MS) and electron probe micro-analysis (EPMA). The selected specimen of this common Chilean gastropod was grown under controlled environmental conditions and precise weekly time-marks were imprinted in the shell with calcein staining. Strontium variations in the shell are too limited to be interpreted in terms of environmental parameter changes. In contrast, Mg incorporation into the shell and growth rate appear to change systematically between night and day. During the day, $\mathrm{Mg}$ is incorporated at a higher rate than at night and this intake seems positively correlated with water temperature. The nightly reduced $\mathrm{Mg}$ incorporation is seemingly related to metabolically controlled processes, formation of organic-rich shell increments and nocturnal feeding activity of the animals. The nyctemeral $\mathrm{Mg}$ changes in the C. concholepas shell revealed in this study might explain at least part of the discrepancies observed in previous studies on the use of Mg as a SST proxy in mollusk shells. In the case of C. concholepas, Mg cannot be used straightforwardly as a SST proxy.
\end{abstract}

\section{INTRODUCTION}

Reconstructions of past sea-surface temperatures (paleoSST) is essential to understand past oceanographic and climatic changes. Part of the paleo-SST proxy data comes from elemental and isotopic geochemical variations in calcified structures of marine organisms (corals-e.g. Tudhope et al., 2001; Yu et al., 2005; Corrège ,2006; foraminiferae.g. Elderfield and Ganssen, 2000; Barker et al., 2005; Schmidt et al., 2006; mollusk shells-e.g. Krantz et al., 1987; Richardson, 2001; Bojar et al., 2004 ). If data inferred

\footnotetext{
* Corresponding author. Fax: +33148025554.

E-mail address: Claire.Lazareth@ird.fr (C.E. Lazareth).
}

from foraminifera in marine sediment cores have provided century to millennia records of oceanographic conditions, mollusk shells may provide different paleoecological and paleoclimatical information at a much higher time-resolution, i.e. at daily to yearly scales ( Jones, 1983; Weidman et al., 1994).

Since Epstein et al. (1953) pioneering work, $d^{18} \mathrm{O}$ has been the most commonly used proxy in attempts to infer SST from mollusk shell analyses (e.g. Andreasson and Schmitz, 1998; Schöne et al., 2004; Chauvaud et al., 2005). In biogenic carbonates, $\delta^{18} \mathrm{O}$ is however dependent on both temperature and salinity variations (Epstein and Mayeda, 1953). Because it is difficult to obtain independent information on $\delta^{18} \mathrm{O}_{\text {water }}$ or on paleosalinities, 
complementary geochemical proxies of SST have been actively sought in biogenic carbonates. Variations in $\mathrm{Mg} / \mathrm{Ca}$ ratios might provide such independent information on paleo-SST ( Klein et al., 1996; Lazareth et al., 2003; Takesue and van Geen, 2004). The Sr/Ca ratio has also been studied for paleo-SST reconstructions, but essentially in corals and sclerosponges aragonitic skeletons (e.g. McCulloch et al., 1994; Haase-Schramm et al., 2003; Rosenheim et al., 2004; Yu et al., 2005 ). In bivalve shells, it is still debated whether $\mathrm{Sr} / \mathrm{Ca}$ ratios reflect SST or if kinetic effects are potentially involved in biomineral $\mathrm{Sr}$ intake (Gillikin et al., 2005; Lorrain et al., 2005; Carré et al., 2006).

The physical and physiological parameters (growth rate changes, $\mathrm{pH}$ variations of precipitating fluids, etc.), commonly grouped under the "vital effect" term, have also to be taken into consideration ifit is shown that they affect the proxy record from bivalve shells (Owen et al., 2002; Lorrain et al., 2004; Geist et al., 2005; Lorrain et al., 2005). Also, growth rate changes or interruptions have to be considered to construct a time-series profile and to correct for time averaging problems (Goodwin et al., 2003 ). In an attempt to obtain an accurate paleo-SST proxy calibration, taking into account daily growth variations, we studied the geochemical variations of a fast growing gastropod, Concholepas concholepason a short time window but at a daily to subdaily resolution. To our knowledge, such high time-resolution has never been reached for geochemical proxy calibration in mollusk shells.

For high temporal resolution records, high-resolution analytical techniques are necessary. With some techniques, a monthly to daily-scale resolution can be reached depending on the growth rate of the chosen species. Laser Ablation Inductively-Coupled Plasma Spectrometry (LA-ICPMS) is becoming increasingly used to obtain geochemical profiles in biocarbonates (e.g. coral skeleton, bivalve shells) for environmental reconstructions. Since the pioneering works of Perkins et al. (1991) and Pearce et al. (1992), LA-ICP-MS trace element studies on biocarbonate concerned both calibration studies (van der Putten et al., 1999; Bellotto and Miekeley, 2000; Craig et al., 2000 ) and applications to environmental and paleoenvironmental reconstructions essentially based on corals (McCulloch et al., 1994; Sinclair et al., 1998; Quinn and Sampson, 2002; Fallon et al., 2003 ) and mollusk shells (Fuge et al., 1993; Raith et al., 1996; Stecher et al., 1996; van der Putten et al., 2000; Lazareth et al., 2003; Takesue and van Geen, 2004; Gillikin et al., 2005 ). These studies have shown that LA-ICP-MS allows accurate determination of trace element variations in the shells at a seasonal scale. Trace element profiles so produced can then reflect environmental changes during the shell formation. Some other studies were performed using Electron Probe Micro Analysis (EPMA) (Rosenberg and Hughes, 1991; Horng-Sheng and Grossman, 1994; Epplé, 2004) which in principle provides very high-resolution profiles. In addition, for elements with concentrations close to $1 \mathrm{wt} \%$, EPMA gives quantitative results at a spatial resolution close to that of LA-ICP-MS. As LAICP-MS biocarbonate analysis still suffers from the lack of appropriate external standards, EPMA analyses can provide an assessment on LA-ICP-MS accuracy, as well as an independent internal standardization for absolute concentration determinations (e.g. Poitrasson et al., 1996; Poitrasson, 2001).

We worked on the shell of C. concholepas [Bruguière, 1789], a large size subtidal endemic gastropod living in the nearshore area along the Peru-Chile coasts (between $\sim 10^{\circ} \mathrm{S}$ and $\sim 55^{\circ} \mathrm{S}$ ). This species has a similar economic importance than the Californian abalone (Haliotis spp.) and lives in comparable bathymetric ranges $(0$ to $-50 \mathrm{~m}$ ) but has quite different ecological niche, $C$. concholepas being a carnivorous predator, while, Haliotis is a grazer.

The northern half of the Peru-Chile area is under the influence of the El Niño phenomenon. Given the absence of other potential proxies like coral skeletons in this region, the C. concholepas species is potentially a promising paleoenvironmental recorder because fossil shells are abundant in archeological sites and in well preserved Pleistocene marine terraces (Labonne and Hillaire-Marcel, 2000 ; Dauphin et al., 2003b ; Guzmán , 2004). This mollusk species also has the advantage of a high growth rate and particularly clear growth patterns, which make it well adapted for geochemical calibration purposes. Growth patterns were examined at the macro-, micro- and nanoscopic scales, with different techniques (Guzmán, 2004; Guzmán et al., 2007). These previous studies partly based on precise chronological control (at the hourly scale) involving fluorochrome staining indicate that $\mathrm{C}$. concholepas shells are susceptible to record continuously temperature variations unlike most mollusk species (see review in Richardson, 2001). The biomineralisation process in the outer calcitic layer of $\mathrm{C}$. concholepas is characterized by the formation at an hourly rhythm (between half-an-hour and $3 \mathrm{~h}$ ) of growth units that measure about two micrometers in thickness (Guzmán, 2004; Guzmán et al., 2007). The pace at which these 21 m-thick units are formed determines the growth rate, which varies throughout the day.

In this geochemical study, Mg and Sr determinations were obtained at a subdaily resolution for one and a half month on a laboratory-grown specimen. Precise temporal framework is provided by successive fluorescent markings of the shell. Reproducibility and accuracy of the geochemical obtained by LA-ICP-MS and EPMA is assessed. The $\mathrm{Mg}$ and $\mathrm{Sr}$ geochemical variations in the shell are then compared with water temperature fluctuations recorded during shell growth with the general aim to verify whether these elements can trace former thermal variations in shells of that species.

\section{MATERIALS AND METHODS}

\subsection{Sample}

The C. concholepas shell study in the present paper relies upon a population experimentally grown and submitted to staining experiments (Guzmán, 2004). The results are herein used to allocate a date to each analysis point, thereby allowing an accurate comparison between geochemical variations and water temperature fluctuations. The detailed description of this experiment and of the growth patterns in the $C$. concholepas shell will be published elsewhere and only the main results are given here. 
From August to December 2002, 85 specimens of C. concholepas were placed in an aquaculture tank at the Marine Resource Faculty of the Antofagasta University under natural light with almost the same length of time for day and night $\left(23^{\circ} \mathrm{S}\right)$. The specimens were fed ad libitum with mytilids (Perumytilus purpuratus). The experimental tank was supplied continuously with sea water and air. To produce temporal milestones in the shells, the organisms were stained through successive immersions in a fluorescent calcein solution (100 ppm) for $3 \mathrm{~h}$ on the 5, 8, 15, 22, 29 of November and 6 and 13 of December 2002 before their sacrifice on December 15. During the whole staining experiment, the water temperature was recorded every ten minutes by an automatic device with a precision of $0.2^{\circ} \mathrm{C}$ ("tidbit" Onset ${ }^{\circledR}$ ).

After superficial cleaning, the shells were cut along the maximum growth axis (Fig. 1 ) and thick polished sections of the most recent part were prepared for microscopic observations and chemical analyses. The shell of one specimen, M77, was selected for chemical analysis investigations because ofits clear growth pattern. Two samples (M77-1 and M77-2) taken on two successive ridges at the edge of the shell (Fig. 1 ) were prepared as described. The C. concholepas shell is made up of two layers. The internal layer is thin and aragonitic whereas the external is thick and calcitic (Dauphin et al., 2003b; Guzmán, 2004; Fig. 2 a). Under blue fluorescent light, shell sections revealed several very distinguished green lines corresponding to the successive calcein stains. Calcein baths for $3 \mathrm{~h}$ done in the morning do appear in the shell close to the middle of translucent increments (Guzmán, 2004) whereas calcein baths done around midnight appear in opaque increments. One day of growth thus results in the accretion of one translucent increment (day) and one opaque one (night) when viewed under diffuse natural light (Fig. 2 c). This gives the temporal framework required for high-spatial resolution geochemical analyses.

\subsection{Analytical methods}

Two high-resolution analytical techniques were used for this geochemical study, Laser Ablation Inductively-Coupled Plasma Spectrometry (LA-ICP-MS) and Electronic Probe Microanalysis
(EPMA). All analyses were done in the external calcitic layer of the C. concholepas specimen studied.

\subsubsection{LASER ablation ICP-MS}

Three LA-ICP-MS profiles along the maximum growth axis were done, one in M77-1 and two in M77-2. For the M77-1 section, analysis points were carefully located to get one analysis per day and another one per night for each 24-h day of growth. This resulted in a zigzag-like profile to avoid point overlapping ( Fig. 2 a). Under the microscope coupled to the LASER device, growth layers do not appear with sufficient clarity to locate the analysis point exactly as wanted. Thus, some points overlapped day/night layers. Moreover, trying to locate the points one per day and one per night is too much time consuming in relation to the final precision of time allocation for each analysis point. Consequently, the two following LA-ICP-MS profiles in M77-2 were done perpendicular to the growth lines, every $65 \mu \mathrm{m}$ (Fig. 2 a). A calendar date, considering the middle of the period of growth sampled, and time interval (in hours) was assigned to each analysis point through microscopic observation, each growth layer being previously dated using the calcein lines in the shell. Analyses along a single growth layer were done to give an indication on intrashell geochemical homogeneity.

The LA-ICP-MS equipment used was a Cetac LSX 200, a frequency quadrupled Nd-YAG operating at $266 \mathrm{~nm}$, coupled with an Elan 6000 (Perkin-Elmer-SCIEX) ICP-MS from the "Laboratoire des Mécanismes de Transfert en Géologie" (LMTG, Toulouse, France). The LASER was operated in the Q-switched mode with a power of $5 \mathrm{~mJ}$ and a repetition rate of $10 \mathrm{~Hz}$. Each analysis was done as a single point and lasted between 50 and $60 \mathrm{~s}$ with the first $6-8 \mathrm{~s}$ as background acquisition (gas blank). LASER operating conditions are summarized in Table 1 . The resulting craters had a diameter of $60 \mu \mathrm{m}$ (Fig. $2 \mathrm{~b}$ ). The element and isotopes analyzed were ${ }^{24} \mathrm{Mg},{ }^{43} \mathrm{Ca},{ }^{44} \mathrm{Ca},{ }^{55} \mathrm{Mn},{ }^{88} \mathrm{Sr},{ }^{137} \mathrm{Ba}$ and ${ }^{138} \mathrm{Ba}$. The signals were integrated on 10-15 $\mathrm{s}$ when stability has been reached (after the initial peak), with the first $5 \mathrm{~s}$ subtracted as blank.

To calculate trace element concentrations in the $C$. concholepas shell, several external standards were tested for calibration: (1) the NIST-610 silicate glass (US National Institute of Standard and Technology); a pressed pellet of (2) GSR-6 limestone (Institute of Geophysical and Geochemical Prospecting, China), (3) a calcite (C1) and (4) a fish otolith CRM-22 (National Institute for Environmental Studies, Japan). The GSR-6 pellet was prepared using $500 \mathrm{mg}$ of powder pressed under a $10-$ ton $/ \mathrm{cm}^{2}$. For $\mathrm{C} 1$ we used a pressure of $8 \mathrm{ton} / \mathrm{cm}^{2}$ on $350 \mathrm{mg}$ and for CRM-22 $10 \mathrm{ton} / \mathrm{cm}^{2}$ on $500 \mathrm{mg}$. Element concentrations of the standards used are reported in Table 2. Five analyses in each standard were done at the beginning of each analytical session to assess reproducibility and
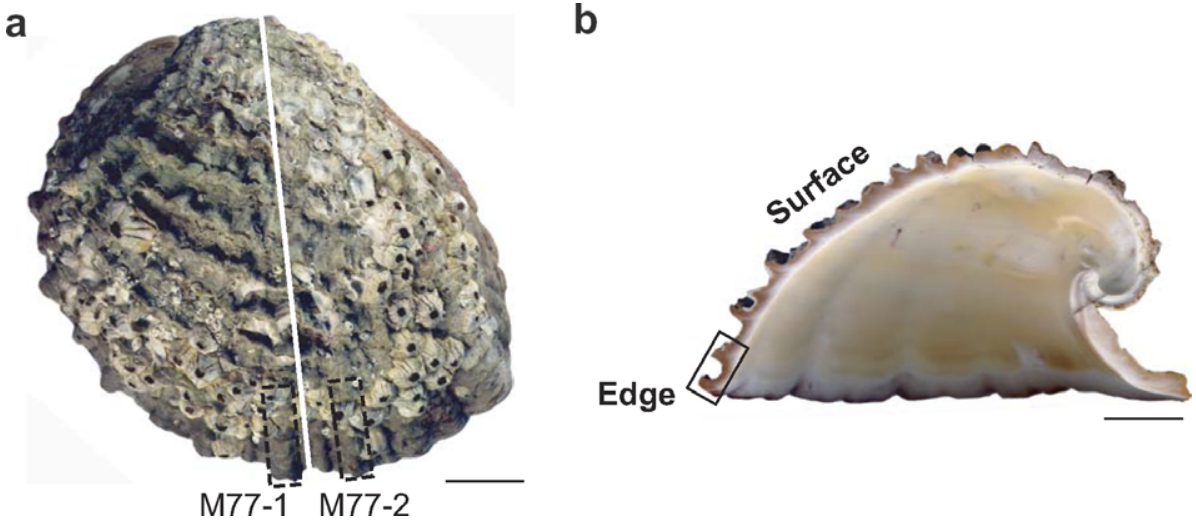

Fig. 1. The Concholepas concholepasspecimen analyzed in this study (scale bars $=1 \mathrm{~cm}$ ). (a) Dorsal view of the shell. White line: maximum growth axis, black broken boxes: samples studied. (b) Cross section of the shell. Black box: position of the M77-1 sample. 

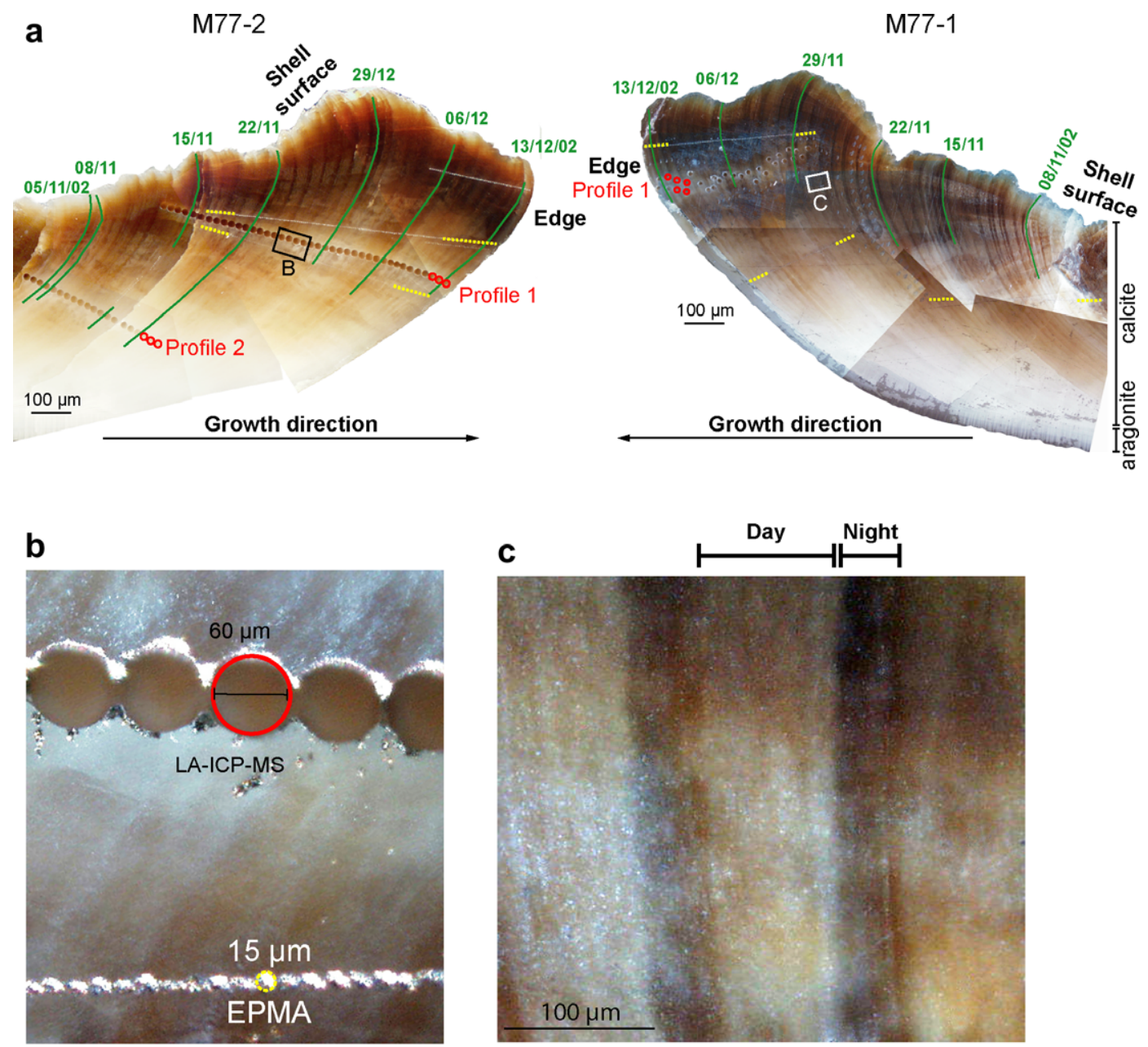

Fig. 2. Cross-section of the Concholepas concholepasshell studied (optical microscope, diffused natural light) after high-resolution analyses. Red circles: LA-ICP-MS, yellow dots: EPMA. (a) Global view of adjacent sections M77-1 and M77-2 showing the subdaily growth pattern and the high-resolution profiles; green line: position and date of the weekly calcein markings. (b) Close-up of the high-resolution spots on the M77-2 section. (c) Close-up of the subdaily growth pattern on the M77-1 section. (For interpretation of the references to color in this figure legend, the reader is referred to the web version of this paper.)

Table 1

LASER probe operating conditions

\begin{tabular}{ll}
\hline LASER mode & Q-switched \\
\hline Laser power & $5 \mathrm{~mJ}$ \\
F requency & $10 \mathrm{~Hz}$ \\
Preablation time (blank) & $6-8 \mathrm{~s}$ \\
A cquisition time (laser firing) & $50-60 \mathrm{~s}$ \\
Crater size & $60 \mu \mathrm{m}$ \\
Objective & $5-10 \cdot$ \\
Depth profiling & $1-5 \mu \mathrm{m} \mathrm{s}^{-1}$ \\
\hline
\end{tabular}

accuracy, and to test standards for calibration. Then, each standard was analyzed every 10 samples for additional correction of possible instrumental drifts and calculation of element concentrations.

\subsubsection{Electron probe microanalysis (EPMA)}

Trace elements were also determined by EPMA for comparison with the LA-ICP-MS analyses. The analyses were performed with a
Table 2

Element concentrations (ppm) of the external standards used for LA-ICP-MS analyses and of the Concholepas concholepas calcite layer (mean solution ICP-MS values)

\begin{tabular}{lccc}
\hline & $\mathrm{Mg}$ & $\mathrm{Ca}$ & $\mathrm{Sr}$ \\
\hline C1 (calcite) & 2240 & 398,100 & 208 \\
GSR-6 (limestone) & 31,300 & 254,800 & 913 \\
CRM-22 (otolithe) & 21 & 388,000 & 2360 \\
NIST 610 (glass) & 465.3 & 81,790 & 497.4 \\
C. concholepas (calcite) & 990 & 37,000 & 1200
\end{tabular}

C1, ICP-MS home-values (M. Valladon - LMTG, Toulouse, personal communication); GSR-6, recommended values from Govindaraju (1994); CRM-22, certified values from National Institute for Environmental Studies (Japan); NIST-610, values from Pearce et al. (1997); C. concholepas. values from Guzmán (2004).

Cameca SX 100 at the "Centre Camparis" (IPG-Paris VI, France). The accelerating potential was set at $15 \mathrm{keV}$, the Farraday cup current at $40 \mathrm{nA}$ for $\mathrm{Ca}$ and $400 \mathrm{nA}$ for $\mathrm{Mg}, \mathrm{Mn}, \mathrm{Sr}$ and $\mathrm{Ba}$. The 
beam was defocused $(10 \mu \mathrm{m})$ and acquisition times were of $10 \mathrm{~s}$ for $\mathrm{Ca}, 20 \mathrm{~s}$ for $\mathrm{Ba}$ and $20-40 \mathrm{~s}$ for $\mathrm{Mg}, \mathrm{Mn}$ and Sr. A diopside and a strontium silicate crystal of known composition were used as standards. The analytical precision expressed as $2 \sigma$ was calculated using the method developed by Ancey et al. (1977). Chemical profiles were conducted on the shell with an automated step of $10 \mu \mathrm{m}$ for one profile and $20 \mu \mathrm{m}$ for the others (Fig. $2 \mathrm{~b}$ ). Six profiles were done, two in M77-1 and five in M77-2. To obtain trace element EPMA time-series, and because the points are small, numerous and regularly spaced, a date was allocated to points close to the calcein lines and the dates in between were interpolated.

With a mean daily growth rate of $95 \mu \mathrm{m}$ day $^{-1}$ for the considered period, the mean temporal resolution obtained is two analyses per day with LA-ICP-MS and ten analyses per day with EPMA.

\section{RESULTS}

Trace element (Mg and $\mathrm{Sr}$ ) profiles were obtained in the C. concholepas shell by using two high-resolution techniques, LA-ICP-MS and EPMA. Barium and Mn were also analyzed using both techniques but remained below detection limits in the $\mathrm{C}$. concholepas shell. Consequently, $\mathrm{Ba}$ and $\mathrm{Mn}$ will not be further discussed.

\subsection{LA-ICP-MS: internal standardization and calibration}

To correct for different ablation yields and loss of sensitivity through time, both ${ }^{43} \mathrm{Ca}$ ( Longerich et al., 1996; Gu" nther et al., 1999; Craig et al., 2000 ) and ${ }^{44} \mathrm{Ca}$ ( Toland et al., 2000; Hendry et al., 2001 ) have been used as an internal standard in LA-ICP-MS analysis of carbonates. The best results are obtained for internal standardization when the analyte and internal standard have a similar behavior vs. time (Longerich et al., 1996). In our case, the ${ }^{44} \mathrm{Ca}$ signal yield was too high in comparison with those of the analytes ofinterest to provide a good internal standard and we thus choose to use ${ }^{43} \mathrm{Ca}$ as internal standard for all of our analyses.

To determine the best external standard for the calibration of the LA-ICP-MS data, the homogeneity of the different standards chosen has been evaluated in comparing the reproducibility of standard analyses. The reproducibility was checked on integrated stable signals after blank subtraction and internal normalization but without external calibration. Reproducibility is expressed as relative standard deviation expressed in percent (RSD).

For GSR-6 $(\mathrm{n}=18)$, reproducibility is above $10 \%$ (Fig. 3 ). Fractionation effects related to variable particles sizes generated by the LASER ablation process have been reported, but these effects have been reported to be negligible for both Sr and Mg ( Guillong and Günther, 2002; Kuhn and Günther, 2004). Even if such particle size fractionation effect cannot be excluded for the GSR- 6 pressed pellet, optical observation of the pellet suggest that it remains heterogeneous because of a powder not fine enough. For C1 $(\mathrm{n}=22), \mathrm{Mg}$ and $\mathrm{Sr}$ reproducibility are around $8 \%$ and $6 \%$ respectively. For CRM-22 ( $n=14)$, only Sr, the most abundant trace element in this substrate, gives good results with a RSD of $5.6 \%$. For NIST-610, reproducibility is below $10 \%(n=19)$. Hendry et al. (2001) obtained similar NIST-610 reproducibility. Better reproducibility, ofless
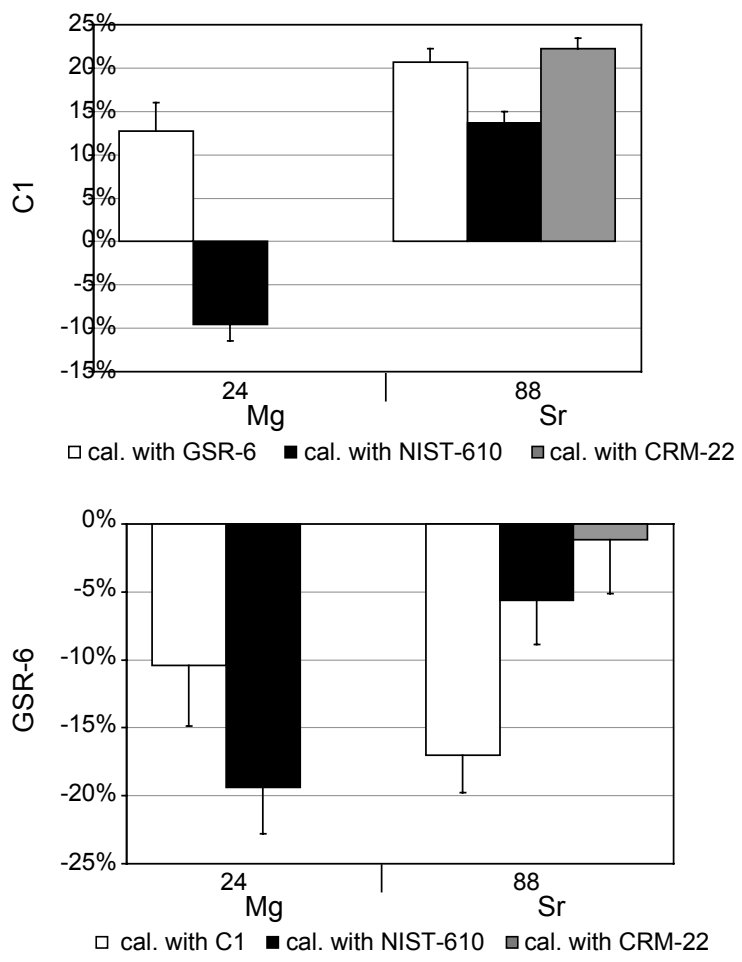

Fig. 3. Mean accuracies of LA-ICP-MS ${ }^{25} \mathrm{Mg}$ and ${ }^{88} \mathrm{Sr}$ data, expressed as the percentage of difference between calculated and recommended values, for C1 and GSR-6 calibrated with different external standards. Standard errors of the means are reported as error bars on the graphs. For C1 calibrated with GSR-6 and NIST$610, n=22$ (8+14 in two sessions), for GSR-6 calibrated with C1 and NIST-610, $\mathrm{n}=18(6+12$ in two sessions) and for $\mathrm{C} 1$ and GSR- 6 calibrated with CRM-22, $\mathrm{n}=14$ and 12 , respectively.

than $5 \%$, was obtained in other studies that used the same type of LASER but under different operating conditions, particularly using lower frequencies $(65 \mathrm{~Hz})$ and energy output (<1-3 mJ) (Norman et al., 1996; Epplé , 2004).

Carbonate reference materials are especially important for external calibration and to check the accuracy of biocarbonate LA-ICP-MS analysis given the difficulty that may be encountered during the LASER ablation of such material. However, use of ultraviolet LASER reduces matrix effects (Geertsen et al., 1994; Günther et al., 1995; Norman et al., 1996). Several types of potential external solid standards have been tested to calibrate analyses of biogenic $\mathrm{CaCO}_{3}$ by LA-ICP-MS. These include silicate glass reference materials (e.g. Price and Pearce, 1997; Hendry et al., 2001; Fallon et al., 2002; Lee et al., 2004 ), "home-made" carbonate standards (Sinclair et al., 1998; Fallon et al., 1999; Bellotto and Miekeley, 2000; Runnalls and Coleman, 2003; Gillikin et al., 2005 ) and geological reference materials (Craig et al., 2000; Toland et al., 2000 ). Rosenheim et al. (2004) used the fish otolith reference material CRM-22 ( Yoshinaga et al., 2000 ) for their sclerosponge LA-ICP-MS study. In the present work, we tested four reference materials, the NIST-610 glass, two geological materials (C1 and GSR-6) and the otolith CRM-22, the latter three as pressed pellets. The choice of an external 
standard for the calibration of the C. concholepas analyses was determined on the basis of the reproducibility discussed above and accuracy of the calibrated analyses. The accuracy of the analyses of $\mathrm{C} 1$ and GSR- 6 was evaluated when calibrated with the two other standards (Fig. 3 ). Accuracy is expressed as the difference between calibrated and known value divided by known value, and expressed in percent. Standard errors of the means of the calibrated data are reported in Fig. 3 and reflect the global reproducibility.

For Mg, accuracies are around 10\%, except for GSR-6 when calibrated with NIST-610 (20\% of difference with the recommended value). The accuracy obtained for GSR-6 when calibrated with NIST-610 is probably linked to the important difference in Mg content between GSR- 6 and NIST-610 (cf. Table 2) but it remains reasonable for this substrate. Craig et al. (2000) obtained differences of $-46 \%$ between measured and recommended contents of Mg in GSR-6 when their LA-ICP-MS analyses were calibrated using a calibration line obtained from different "home-made" synthetic pressed-powder pellet calibrations. When the LA-ICP-MS data were calibrated using reference material calibration line, Craig et al. (2000) obtained almost no difference between recommended and measured GSR-6 Mg content. But, in this last case, the reference material calibration line used to calibrate GSR- $6 \mathrm{Mg}$ data already includes the GSR- 6 material (see Table 6 in Craig et al., 2000). The highly accurate result obtained in their study for Mg GSR- 6 when using the reference material calibration line is probably related to the fact that GSR-6 was partly calibrated against itself.

For Sr, accuracies obtained for C1 and GSR-6 when calibrated with different external standards are variable; only the NIST-610 calibration gives values systematically within less than $15 \%$ of difference with recommended values (Fig. 3 ). The accuracies obtained on GSR-6 Sr data are better than those obtained by Craig et al. (2000) whatever the calibration line they used. The improvement is especially obvious for calibration with NIST-610 and CRM-22.

Consequently, given the reproducibility and accuracy obtained, the NIST-610 standard was chosen for calibration in this study. This calibration procedure has been verified by standard liquid ICP-MS analyses on micromilled powders sampled on another section of the same shell (Electronic annex, EA-1 ). Absolute trace element contents in the $C$. concholepas shell were calculated using the mean of NIST-610 analyses bracketing the different profiles. When a signal bias of more than $5 \%$ was observed on NIST-610 data, calibration calculations were performed on sub-sections of the profiles. The mean Ca content of the shell part analyzed with EPMA ( $\mathrm{Ca}=38.2 \pm 0.3 \%)$ was used in the internal standardization for calculation of $\mathrm{Mg}$ and $\mathrm{Sr}$ concentrations.

\subsection{Growth and temperature variations}

For convenience and consistency in the following sections, we will use the term "day" for the period with natural sunlight as opposed to the term "night". The adjective "daily" will be used when both "day" and "night" are taken into account, from one morning to the next one (24-h).
To evaluate the possible implications of growth rate variations on geochemical changes in the shell, daily growth was measured under the microscope as the thickness (in $\mu \mathrm{m}$ ) of one couplet of translucent and opaque increment. In addition, day vs. night growth was measured as the thickness of translucent and opaque increments respectively (two growth values per day, $\mathrm{Gr}_{\text {day }}$ and $\mathrm{Gr}_{\text {night }}$ ). Daily growth varied between $19 \mu \mathrm{m}$ to $150 \mu \mathrm{m}$. A Mann-Whitney test $(p<0.05)$ shows that growth during day (mean $\mathrm{Gr}_{\text {day }}=50 \pm 9 \mu \mathrm{m}, 1$ standard deviation, SD) is significantly faster than growth during the night (mean $\mathrm{Gr}_{\text {night }}=34 \pm 8 \mu \mathrm{m}, 1 \mathrm{SD}$ ).

The recorded water temperature increased regularly from 17 to $22{ }^{\circ} \mathrm{C}$ during the month and a half experiment with several peaks ( $1{ }^{\circ} \mathrm{C}$ in range) in between, the broadest one occurring between the 5th and 10th of December 2002 (see Fig. 7 a). To compare the recorded water temperature with shell growth, we compute mean daily water temperature (from 6:00 to 6:00 next day) as well as mean day and night water temperature $\left(T_{\text {day }}=\right.$ from $6: 00$ to $18: 00$, $T_{\text {night }}=$ from 18:00 to 6:00) for each day of growth.

No relation was found between daily growth and daily water temperature. When the data are grouped in terms of day and night, $\mathrm{T}_{\text {day }} / \mathrm{Gr}$ day and $\mathrm{T}_{\text {night }} / \mathrm{Gr}_{\text {night }}$, these two groups are significantly different (discriminant analysis, $\mathrm{p}<0.05)$. No relation was found between $\mathrm{Gr}$ day and $\mathrm{T}_{\text {day }}$ (Fig. 4 a) whereas $12 \%$ of the variability of $\mathrm{Gr}$ night can be explained by $\mathrm{T}_{\text {night }}$ changes with a weak, but significant $(p<0.05)$ positive linear relationship $\left(r^{2}=0.12\right)$ ( Fig. $\left.4 b\right)$.

\subsection{Trace element profiles}

\subsubsection{Strontium}

The mean $\mathrm{Sr}$ concentration of the $\mathrm{C}$. concholepas shell measured by LA-ICP-MS is of $1045 \pm 83$ ppm (1 standard deviation, SD). The RSD of the LA-ICP-MS analyses of Sr content along a single growth layer is of $4 \%(n=16)$ and of $8 \%$ when crossing the growth lines. Furthermore, the analytical error on NIST-610 LA-ICP-MS Sr measurements is of $6 \%$. Consequently, $\mathrm{Sr}$ content can be considered as homogeneous and variations observed using LA-ICP-MS can hardly be considered as significant. The mean Sr content in the $C$. concholepas shell as measured by EPMA is of $1272 \pm 210$ ppm (1SD). Three profiles were not considered because $\mathrm{Sr}$ concentrations measured by EPMA were below detection limits $(840 \mathrm{ppm})$. The mean standard deviation for EPMA is $125 \mathrm{ppm}$. Electron microprobe $\mathrm{Sr}$ variations are thus not significant (Fig. 5 ). The mean $\mathrm{Sr}$ abundance measured by EPMA is higher by $18 \%$ than LA-ICP-MS determinations (Wilcoxon-Mann-Whitney test, $p<0.05)$. Strontium contents in the $C$. concholepas shell studied were also measured by standard liquid ICPMS technique and the results confirm the values obtained by LA-ICP-MS ( EA-1 ). On the other hand, the measurements of $\mathrm{Sr}$ content on the $\mathrm{C}$. concholepas shell using EPMA appears too high. This is probably because the $\mathrm{Sr}$ contents of the shell are too close to EPMA detection limits. This is confirmed by the lack of agreement between the $\mathrm{Sr}$ variations found along the profiles with the two analytical technique used. 

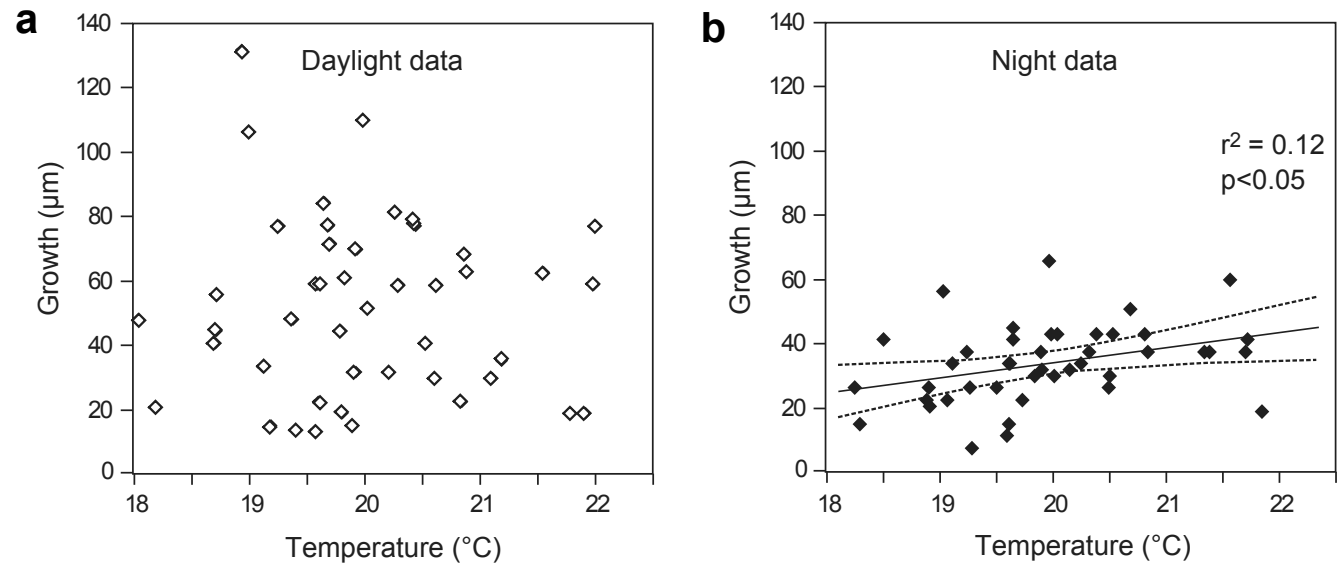

Fig. 4. Relation between water temperature andConcholepas concholepas shell growth. (a) Daylight data (water temperature mean from 6:00 to 18:00 h; growth: thickness of translucent increments). (b) Night data (water temperature mean from 18:00 to 6:00 h; growth: thickness of opaque increments) with least square correlation line and 95\% confidence level (dotted lines).

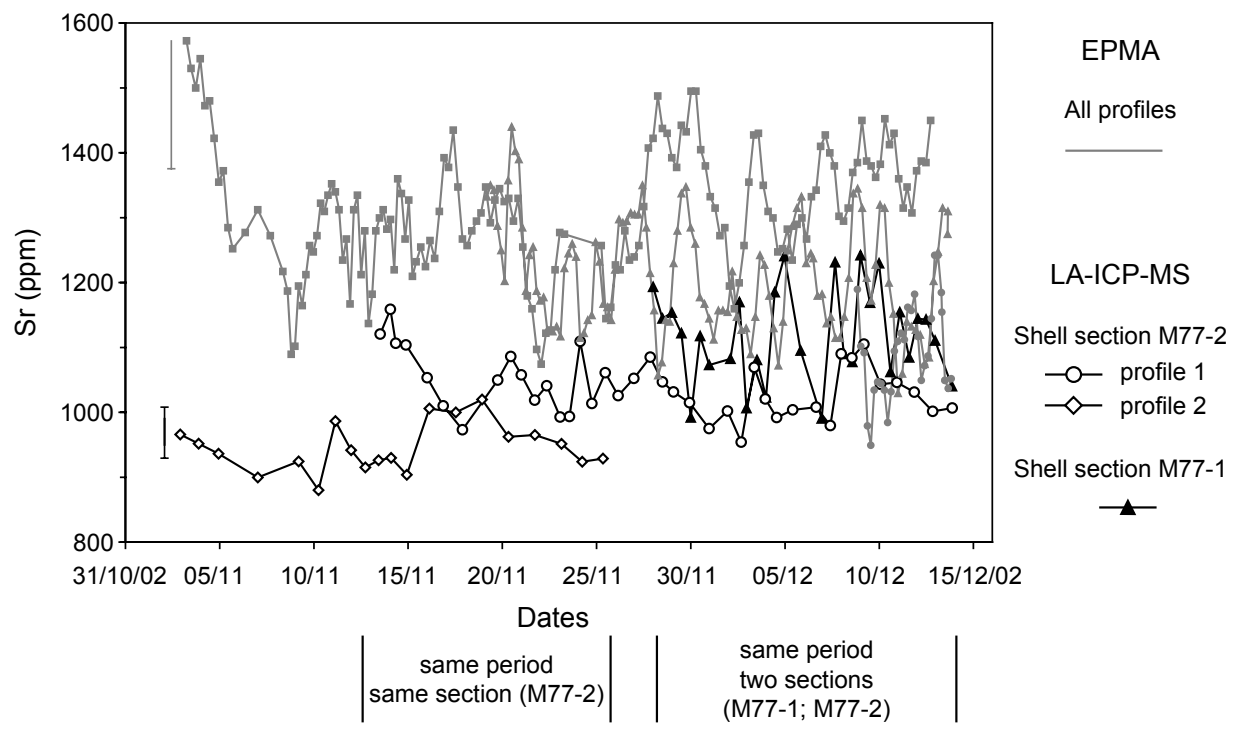

Fig. 5. Strontium profiles in the Concholepas concholepasshell obtained by LA-ICP-MS and EPMA (data smoothed using a four points running average; distinct profiles are represented by different symbols; seeFigs. 1 and 2 for location). LA-ICP-MS error bar = Sr RSD along a single growth line (4\%); EPMA error bar: mean analytical standard deviation.

\subsubsection{Magnesium}

The mean abundance of $\mathrm{Mg}$ in the $\mathrm{C}$. concholepas shell, as measured by using LA-ICP-MS, is $487 \pm 201$ ppm (1SD; $41 \%$ of RSD). Magnesium variations observed by LA-ICPMS ( Fig. 6) are highly significant as the RSDs of the LAICP-MS analyses of Mg content along a single growth layer and the analytical error on NIST-610 LA-ICP-MS are only of $8 \%$. Further, two parallel LA-ICP-MS profiles in the same shell section M77-2 show that these Mg variations reproduce well within the same growth period (Fig. 6). On the other hand, results for the same growth period but in two different sections, M77-1 and M77-2, show slight differences between $28 / 11$ to $08 / 12 / 02$ fig. 6 ). This is probably because of the larger distance between the two profiles (Fig. 1 ). Magnesium profiles measured by EPMA are highly noisy and are presented as a 4 point running average in the
Fig. 6. The mean analytical standard deviation for EPMA $\mathrm{Mg}$ analyses is $20 \mathrm{ppm}$. The general pattern shown by EPMA and LA-ICP-MS for the month-and-a-half period is roughly similar ( Fig. 6 ). Magnesium variations across the analyzed part of the shell display four maxima (excluding the margin of the shell) more clearly shown by LA-ICPMS, with an amplitude decreasing through time of shell formation (i.e., from left to right on Fig. 6 ).

To compare geochemical variations with water temperature fluctuations, we calculated a mean recorded temperature for the time interval sampled for each LA-ICP-MS analysis point. No correlation is found between $\mathrm{Mg}$ content and water temperature (Fig. $7 \mathrm{a}$ ). The $\mathrm{Mg}$ variations of the C. concholepas shell analyzed do not follow the water temperature increase during the month-and-a-half recorded and do not display significant variations during the water 


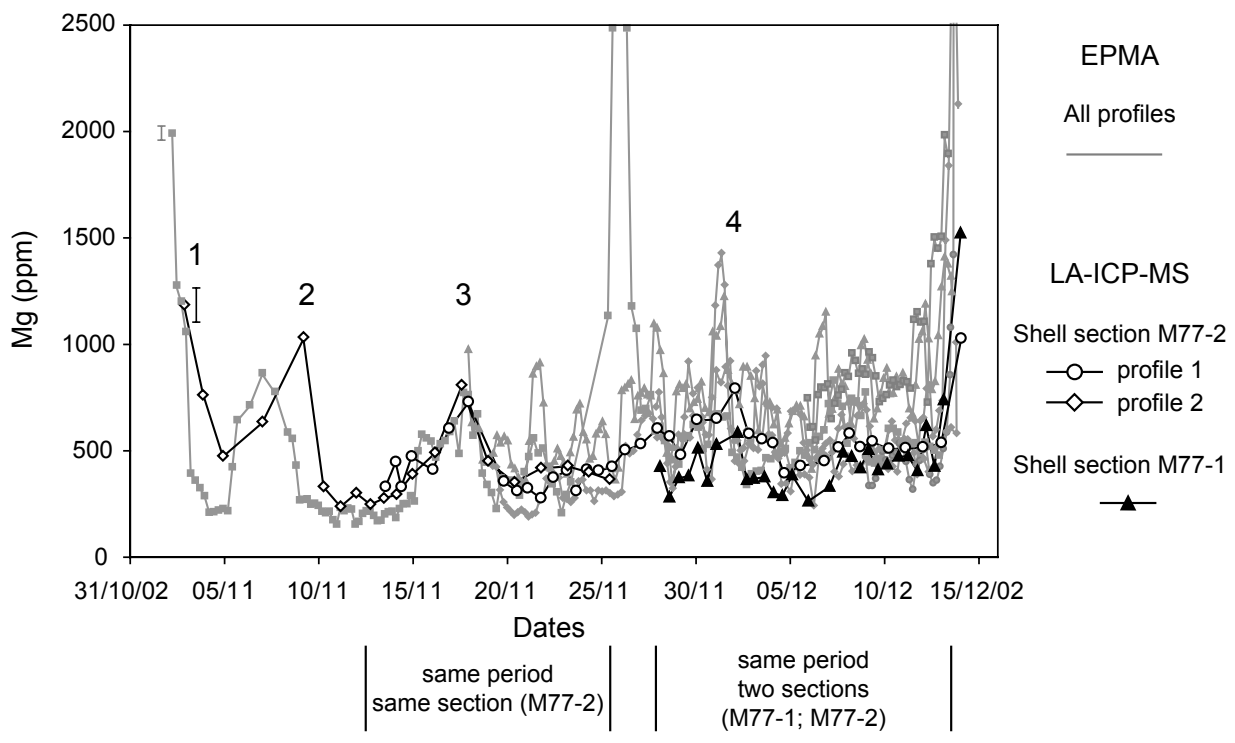

Fig. 6. Magnesium variations in the Concholepas concholepasshell obtained by LA-ICP-MS and EPMA (data smoothed using a 4 points running average, different profiles are represented by different symbols; seeFigs. 1 and 2 for location) measurements. LA-ICP-MS error bar = NIST-610 Mg RSD (8\%); EPMA error bar: mean analytical standard deviation; numbers 1-4 correspond to the maxima described in the Section 3.

temperature peaks observed. Furthermore, no clear relation is found between $\mathrm{Mg}$ variations and daily growth changes either (Fig. 7 b).

To better understand the $\mathrm{Mg}$ incorporation processes into the shell, we separated, through optical-microscope observation of the M77-1 and M77-2 profiles, Mg analyses that covered mainly day shell formation ( $[\mathrm{Mg}]$ day) from those that correspond mainly to night increments $\left([\mathrm{Mg}]_{\text {night }}\right)$. It appears that the mean $[\mathrm{Mg}]_{\text {day }}$ content $\left([\mathrm{Mg}]_{\text {day }}=396 \pm 21 \mathrm{ppm}, 1 \mathrm{SE}\right)$ is significantly lower than the mean $[\mathrm{Mg}]_{\text {night }}$ content $\left([\mathrm{Mg}]_{\text {night }}=521 \pm 30 \mathrm{ppm}, 1\right.$ $\mathrm{SE}$; t-test, $\mathrm{p}<0.05)$. When the water temperature and $\mathrm{Mg}$ day vs. night are considered, no relation between $[\mathrm{Mg}]_{\text {night }}$ and $T_{\text {night }}$ is observed. In contrast, a weak but significant positive relationship between $[\mathrm{Mg}]_{\text {day }}$ and $\mathrm{T}_{\text {day }}$ is observed $\left(r^{2}=0.30 ; p<0.05\right)$ (Fig. 8 ). No relation between Mg content and growth rate was found for both day and night.

\section{DISCUSSION}

\subsection{Analytical and intra-shell reproducibility}

In this study, the mean $\mathrm{Sr}$ abundance measured by EPMA is $18 \%$ higher than that determined by LA-ICPMS. No such large differences between the two techniques and for the different LA-ICP-MS profiles are observed for Mg. Furthermore, standard liquid ICP-MS analyses on the same sample do validate the Sr content as determined by LA-ICP-MS. On Arctica islandica shells, Epplé (2004) also obtained EPMA analyses of Sr content that appeared to be $14 \%$ higher than measurements made by LA-ICP-MS on the same samples. The agreement between LA-ICP-MS/ ICP-MS suggests that the observed inconsistencies between analytical techniques on $\mathrm{Sr}$ abundance in $\mathrm{C}$. concholepas shell are probably linked to calibration problems of the
EPMA technique for $\mathrm{Sr}$ in biocarbonates. In our experiment with $C$. concholepas, we found no significant changes in $\mathrm{Sr}$ concentrations in the shell. Consequently, either $\mathrm{Sr}$ incorporation is not influenced by water temperature or shell growth variations, or environmental/physiological changes were to low to impact Sr incorporation into the shell.

The results of EPMA Mg measurements in the C. concholepas shell are particularly noisy. These variations show that the incorporation of $\mathrm{Mg}$ into the shell does occur at the same timescale as the biomineralisation processus, which is hourly in the case of $C$. concholepas. With the EPMA setting used, the rough correspondence observed between EPMA and LA-ICP-MS Mg variations suggests that EPMA might be used to obtain Mg profiles in biocarbonates with a very-high spatial resolution provided analytical improvements. For the same period of growth (13/11 to 25/ $11 / 02$ ) of the section M77-2, Mg variations obtained for two overlapping LA-ICP-MS profiles are identical (Fig. 6 ). In distinct sections close to the maximum growth axis (M77-1 and M77-2), similar Mg results are obtained. The $\mathrm{Mg}$ variations in the $\mathrm{C}$. concholepas shell are therefore spatially reproducible. This demonstrates that, in our case, interpretation of shell $\mathrm{Mg}$ variations as an environmental proxy is reliable whatever the considered section of the shell, at least for transects close to the maximum growth axis.

4.2. The C. concholepas external shell layer: a very-low $\mathrm{Mg}$ calcite

In this study, the mean $\mathrm{Mg}$ content of the calcite layer of the C. concholepas shell ( $\sim 500$ ppm with both techniques used) compares well with values previously obtained in other C. concholepas shells ( $\sim 700$ ppm by using Energy Dis- 

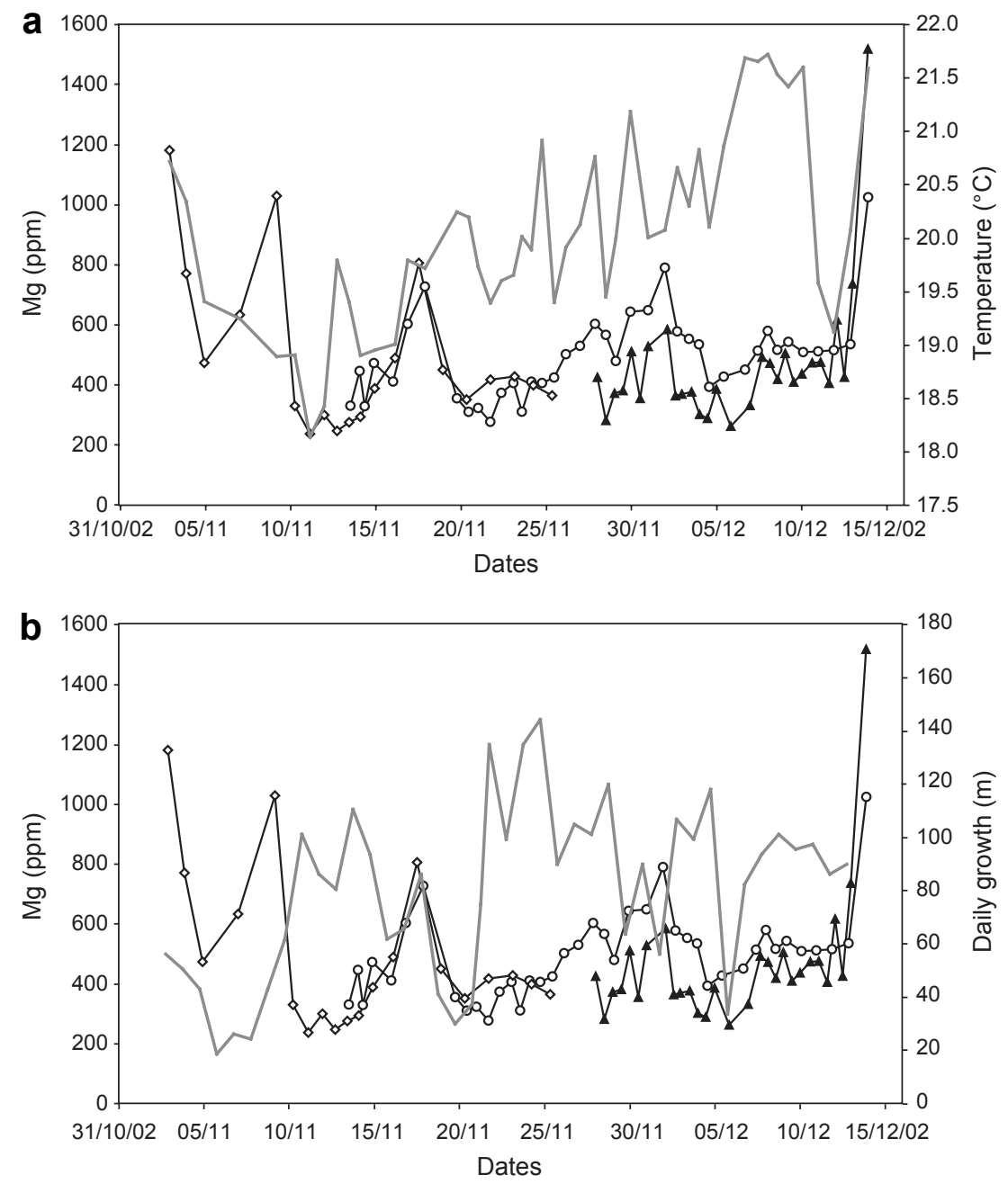

Fig. 7. Comparison between high-resolution measurements of Mg variations determined by LA-ICP-MS in the Concholepas concholepas shell (lines with symbols, same as Fig. 6 ) with thermal and growth rate data. (a) Plot of Mg and water temperature (gray line) vs. time. (b) Plot of Mg and daily growth (black line) vs. time.
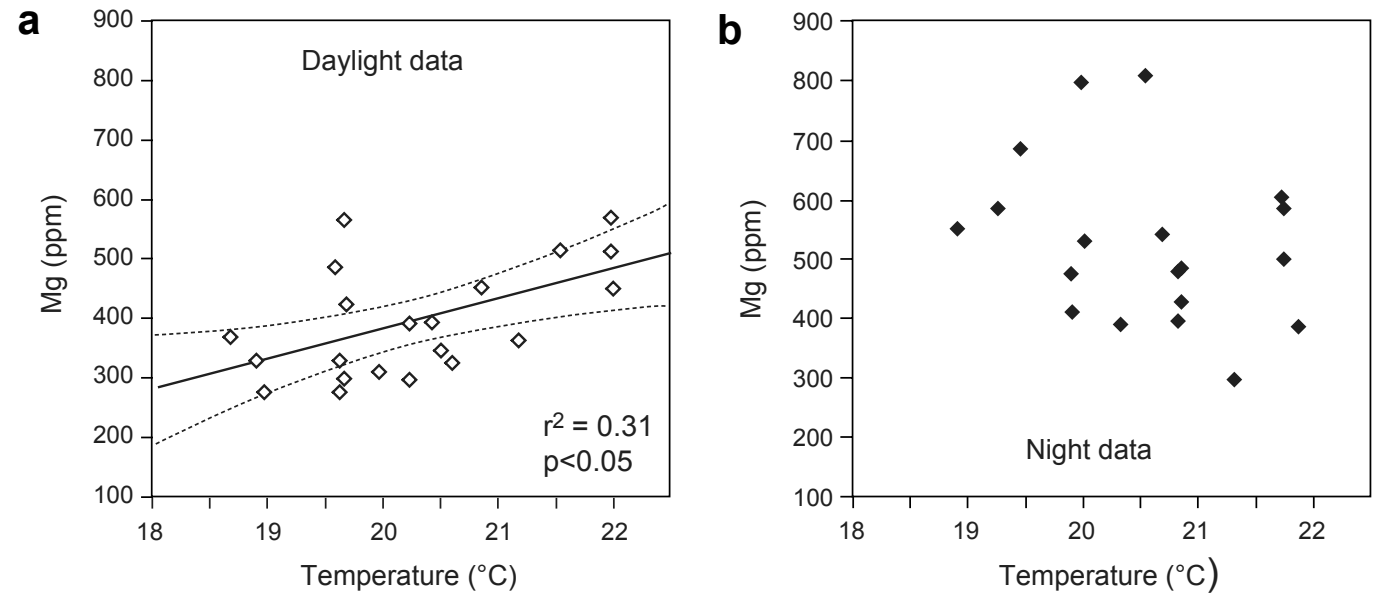

Fig. 8. Relationship between water temperature and Mg abundance in the Concholepas concholepasshell, measured by LA-ICP-MS, at the nyctemeral rhythm. (a) Daylight data with least-square correlation line and 95\% confidence level (dotted lines). (b) Night data. 
persive Spectroscopy in Dauphin et al., 2003b ; between 500 and 1000 ppm by EDS and solution ICP-MS in Guzmán, 2004). This Mg content corresponds to a mean $\mathrm{Mg} / \mathrm{Ca}$ ratio around $2 \mathrm{mmol} / \mathrm{mol}$, a low value when compared with other calcitic mollusks (e.g. Masuda and Hirano, 1980; Klein et al., 1996; van der Putten et al., 2000; Freitas et al., 2005; Lorrain et al., 2005 ; Fig. 9), or even those referred to as low-Mg calcite species (e.g. rudists, Immenhauser et al., 2005; Steuber and Rauch, 2005 ), and to foraminifera ( Nü rnberg et al., 1996; Lea et al., 1999; Lear et al., 2002). This very low $\mathrm{Mg}$ content in the C. concholepas calcitic layer is actually comparable to those reported for aragonite biocarbonates, which is around $2 \mathrm{mmol} / \mathrm{mol}$ for aragonitic bivalves (e.g. Foster and Cravo, 2003; Takesue and van Geen, 2004; Gillikin et al., 2005 ), around 4$5 \mathrm{mmol} / \mathrm{mol}$ in corals (e.g. Quinn and Sampson, 2002; Kilbourne et al., 2004) and around $1 \mathrm{mmol} / \mathrm{mol}$ for sclerosponges (e.g. Rosenheim et al., 2005) (Fig. 9). Lorens and Bender $(1977,1980)$ postulated that Mytilus edulis physiologically exclude $\mathrm{Mg}$ from their extrapalleal fluid to precipitate their calcite shell. The Mg partition coefficient, $D_{M g}=(M g / C a)_{\text {calcite }} /(\mathrm{Mg} / \mathrm{Ca})_{\text {seawater }}$ for the $C$. concholepas calcite layer is of $0.04 \cdot 10^{-2}$ (using a $\mathrm{Mg} / \mathrm{Ca}$ seawater value of $5.15 \mathrm{mmol} / \mathrm{mol}$; Broecker and Peng, 1982), lower than that observed for M. edulis (0.12-0.13 $\cdot 10^{-2}$; Lorens and Bender, 1980; Gillikin, 2005 ) and far lower than that ofinorganic precipitated calcite (1.7 $10^{-2}$; Mucci, 1987). This might indicate a strong physiological control of $\mathrm{Mg}$ incorporation into the C. concholepas shell.

4.3. Magnesium incorporation in C. concholepas a complex processes at a nyctemeral rhythm

Microgrowth increment studies on molluskan shells have led to conclude that growth lineation is a reflection of the alternation of "calcium-carbonate-rich" and "organic-rich" regions ( Lutz and Rhoads, 1980 ). This succession of more or less organic-rich increments has been observed using different methods (optical and electron microscope) and shell preparations (thin sections, acetate peels, etc.). For C. concholepas shells, daily growth results in the accretion of one translucent and one dark increment when viewed with an optical microscope under diffused light. Staining experiments showed that translucent increments correspond to shell growth during the day and that opaque increments correspond to shell growth during the night. Darker increments are usually interpreted as organic rich laminae in mollusks shell (e.g. Pirker and Schiel, 1993; Shepherd et al., 1995) and otoliths (e.g. Panella, 1980; Morales-Nin, 1987; Wright et al., 2002 ). It has been established that sulfur is associated with the organic phase in biocarbonates, both corals and mollusks (Lorens and Bender, 1980; Rosenberg et al., 2001; Dauphin et al., 2003a; Cuif and Dauphin, 2005; Dauphin et al., 2005 ). The $S$ is present

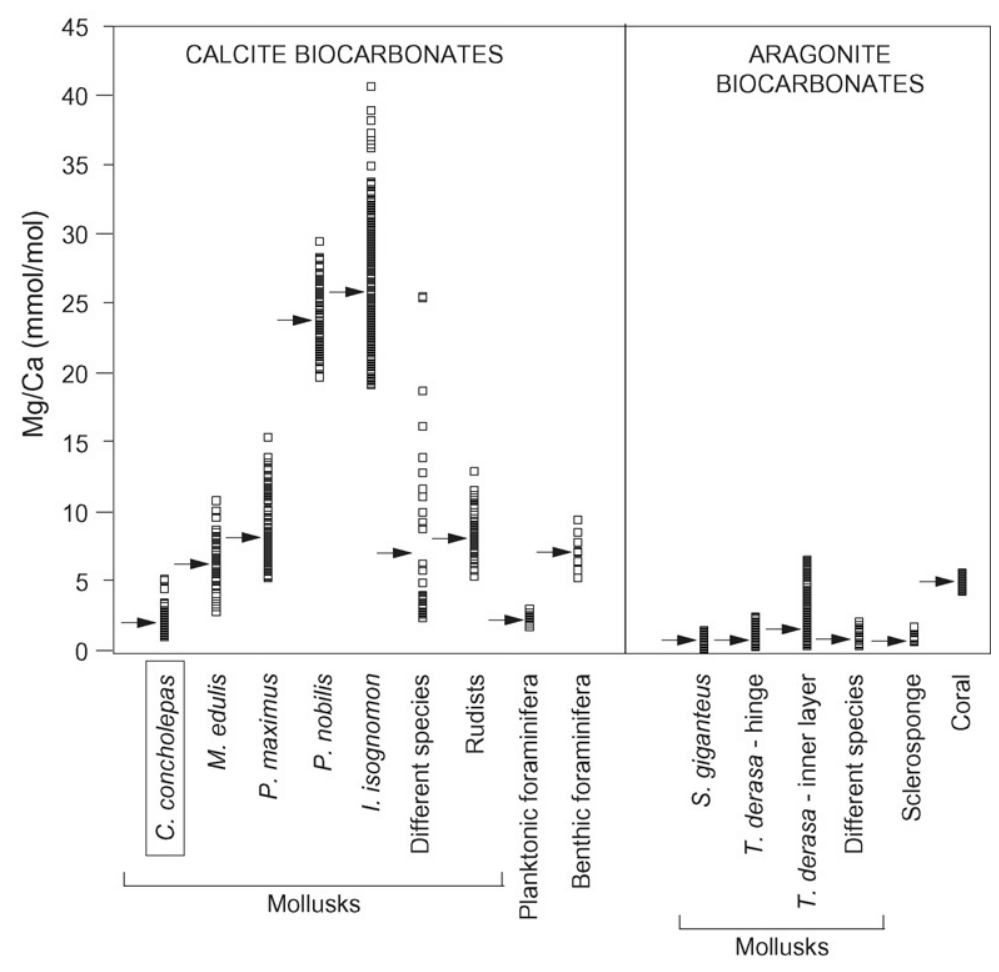

Fig. 9. Comparison of Mg/Ca ratios from the calcitic layer of Concholepas concholepas (this study; LA-ICP-MS data) with Mg/Ca from other biominerals. Squares: Mg/Ca values; arrows: point average values. Other calcite data from: bivalves ( Mytilus edulis, Klein et al. (1996) ; Pecten maximus, Lorrain et al. (2005) ; Pinna nobilis, Freitas et al. (2005) ; Isognomon ephippiumEA-2 ; different species, Masuda and Hirano (1980) ; rudists, Immenhauser et al. (2005)) and foraminifera ( Lear et al., 2002; Anand et al., 2003 ; calculated for temperatures between 17 and $23^{\circ} \mathrm{C}$ ). Aragonite data from: bivalves ( Saxidomus giganteus Gillikin (2005) ; Tridacna derasa, Elliot, personal communication), gastropod species (Foster and Cravo, 2003 ), Ceratoporella nicholsoni sclerosponge (Rosenheim et al., 2005) and Porites lutea coral (Quinn and Sampson, 2003). Arrow: mean value. 
as sulfated polysaccharides which repartition is directly related to growth layers (Cuif et al., 2003; Guzmán et al., 2007). Guzmán et al. (2007) evidenced the sulfated polysaccharide nature of $S$ in $C$. concholepas and its link with the shell banding pattern (see Fig. 9 in Guzmán et al., 2007). An EPMA map of $S$ distribution, that will be published elsewhere, shows that dark increments in C. concholepas shell have a higher $S$ content than translucent ones. The fact that $S$ is well linked to growth layers and microstructural organization, together with Guzmán et al. (2007) results, strongly suggests that it is linked to biological growth process and in this way it can not be considered as "pure mineral" nature. At last, several C. concholepas shell samples were etched using the "Mutvei's solution" that includes glutaraldehyde, a fixative molecule that reduces the solubility of organic compounds (Schöne et al., 2005). The etched samples observed by scanning electron microscopy reveal that translucent growth layers were more sensible to etching, meanwhile dark growth layers were less attacked and their homogeneity was preserved. Thus, C. concholepas dark increments that correspond to night shell growth are richer in organic matrix than the translucent (day shell growth) increments.

In the C. concholepas shell studied, distinct processes are at work at a nyctemeral rhythm, in terms of global Mg content and growth. The $C$. concholepas shell exhibits a faster growth during the day $\left(\mathrm{Gr}_{\text {day }}=50 \pm 9 \mu \mathrm{m}\right.$; 1SD) than during the night $\left(\mathrm{Gr}_{\text {night }}=34 \pm 8 \mu \mathrm{m}\right.$; 1SD), when opaque, organic-rich increments are observed. From their study on M. edulis shell metabolism, Rosenberg and Hughes (1991), conclude that "matrix-rich shell is metabolically more expensive to produce than mineral-rich shell", an affirmation supported by Palmer (1983, 1992). While Palmer (1983, 1992) works rely on populations and whole shells studies, Rosenberg and Hughes (1991) made their observation on different parts, close to the umbo/slow growth vs. edge/fast growth, of $M$. edulis shells. Rosenberg and Hughes (1991) found high Mg and S content close to the slow growing umbo, where they previously revealed a high mantle metabolism activity (Rosenberg et al., 1989). In the case of $C$. concholepas, this is somehow different because various Mg content, organic-phase richness and shell growth are observed in the shell at the nyctemeral scale. Nevertheless, if we transpose to this study the Rosenberg and Hughes (1991) metabolic model, we would then interpret that the metabolic activity of the mantle of $C$. concholepas changes at a subdaily rhythm, with a high metabolic activity at night (high $\mathrm{Mg}$, low growth rate, high organic content) and a low metabolic activity during daytime (low $\mathrm{Mg}$, high growth rate, low organic content).

For a more accurate interpretation in terms of different metabolic activity between night and day, we consider the Mg flux into the shell. The experiment took place under natural light at $23^{\circ} \mathrm{S}$ at a time when daylight and night were almost equal. Because the $C$. concholepas shell formation is an hourly process (Guzmán et al., 2007), we made the assumption that translucent (day) and dark (night) increments represent the same amount of time $(12 \mathrm{~h})$. Consequently, a LASER ablation crater of $60 \mu \mathrm{m}$ of diameter centered on an increment formed during the day generally encompasses less than $12 \mathrm{~h}$ of shell formation. We thus estimate the amount of $\mathrm{Mg}$ incorporated into the shell per hour (Mg flux), for day vs. night analyses, as the content of $\mathrm{Mg}$ measured by LA-ICP-MS divided by an estimation of the mean number of hours of shell formation sampled (mean of $12 \mathrm{~h}$ per night analysis vs. mean of $9 \mathrm{~h}$ per day analysis for a $60 \mu \mathrm{m}$ analysis point). It appears that this proxy of the Mg flux into the shell during night growth ( $\sim 35 \mathrm{ppm} /$ h) is lower than that of the day Mg flux into the shell ( $45 \mathrm{ppm} / \mathrm{h}$ ).

What could explain such a difference between day and night $\mathrm{Mg}$ intake in the shell carbonate? As stated before, a matrix-rich shell portion is more metabolically expensive to produce than a shell portion with less matrix content. The production of the nocturnal organic rich increments of the $C$. concholepas shell thus requires a larger amount of energy. In addition, during several years of growth experiment on many individuals of $C$. concholepas at the University of Antofagasta facilities, we observed that the animals ate almost exclusively at night. Clearly, C. concholepas spends much more energy at night, moving and eating, while the individuals keep still during the day. The primary energy provider in all organisms is the adenosine triphosphate (ATP) molecule. The formation of this molecule mainly derives from the catabolism of carbohydrates. The reactions that imply ATP need $\mathrm{Mg}^{2+}$ as a cofactor. We can assume that during the night the high amount of energy needed by theC. concholepas for locomotion, nutrition and organic-matrix rich shell formation involves more ATP molecules than during less active daylight periods. Concerning the matrix-rich shell formation, this hypothesis is supported by the work of Wilbur and Saleuddin (1983) that showed that more ATP molecules are needed to produce protein than to produce calcium carbonate. As $\mathrm{Mg}^{2+}$ ions are required for the use of ATP, we suggest that $\mathrm{Mg}^{2+}$ ions are more specifically allocated for the production of energy during the night, thereby explaining the less important flux of $\mathrm{Mg}$ into the shell grown during the same period. This hypothesis can explain the different relationships between $\mathrm{Mg}$ and water temperature during the day and at night. If shell $\mathrm{Mg}$ incorporation process is preferentially controlled by metabolism during the night, we can assume a minor control of the organism metabolism on $\mathrm{Mg}$ during the day, when $\mathrm{C}$. concholepas is motionless and when less organic-rich shell is formed. As we observe a positive relation between water temperature and $\mathrm{Mg}$ for day data only, it might be interpreted that water temperature influence on shell $\mathrm{Mg}$ incorporation is more important during the day. Finally, we surmise that the weak but significant positive relationship between water temperature and growth during the night probably reflects an increase of metabolic efficiency with water temperature.

\subsection{Implications for paleo-SST reconstructions}

The complexity of the nyctemeral interrelation between water temperature, growth and shell $\mathrm{Mg}$ incorporation revealed in this study can explain the difficulties encountered in the use of mollusk shell Mg content as a proxy for SST reconstructions. For calcite mollusks, the use of shell 
$\mathrm{Mg} / \mathrm{Ca}$ ratio as SST proxy is still debated. Klein et al. (1996) found a significant positive relation between Mg/ $\mathrm{Ca}$ and SST in Mytilus trossulus and then used the equation established to conduct paleo-SST and paleo-salinity reconstructions by combining $\mathrm{Mg} / \mathrm{Ca}$ and $\delta^{18} \mathrm{O}$ profiles from fossil M. trossulus (Klein et al., 1997 ). In Isognomon ephippium shells from Kenya, Mg variations were shown to closely follow those of SST ( Lazareth et al., 2003 ). However, other studies point to the non-systematic relationship between $\mathrm{Mg} / \mathrm{Ca}$ ratio and SST, for single individuals as well as between individuals. From a one year study of growth of M. edulis, van der Putten et al. (2000) observed a positive correlation between $\mathrm{Mg} / \mathrm{Ca}$ and SST only during spring. Similarly, Freitas et al. (2005) showed that in several Pinna nobilis shells, a reliable SST can be calculated from $\mathrm{Mg} / \mathrm{Ca}$ ratios only for the first 4.5 years of growth. An increasing ontogenetic effect was evidenced after this early growth phase of the P. nobilis shells. In an earlier work, Richardson et al. (2004) also evidenced a positive relation between Mg/ $\mathrm{Ca}$ and SST for the first, or two first year(s) of growth of some $\mathrm{P}$. nobilis shells, but the different $\mathrm{Mg} / \mathrm{Ca}$ ratios observed between different specimens growing at the same time led the authors to conclude that it was not possible to deduce an accurate SST directly from $\mathrm{Mg} / \mathrm{Ca}$ records. It is thus clear that the $\mathrm{Mg}$ (or $\mathrm{Mg} / \mathrm{Ca}$ ) relationship with SST is species-dependent and that Mg incorporation in calcite shells is also physiologically controlled. To our knowledge, no other studies investigated the $\mathrm{Mg}$ variations in calcite shells at the subdaily resolution as done in the present study, but the nyctemeral difference observed in the $C$. concholepas shell may exist in other species. This can explain at least some of the discrepancies observed between shell $\mathrm{Mg}$ (or $\mathrm{Mg} / \mathrm{Ca}$ ) contents and paleo-SST reconstructions. Our results show that for species like C. concholepas it is important to take into account the period of the day corresponding to the area analyzed (i.e. translucent vs. opaque bands) to produce meaningful paleo-SST reconstructions. Similar studies are needed on other C. concholepas specimens but also for other species of mollusks before a generalization of the processes and mechanisms proposed here can be extrapolated. In the same way, other hypothesis, as changes in saturation state of the calcifying fluid, could explain Mg/Ca differences within the growth layers, but research needs to be extended in this sense.

\section{CONCLUSIONS}

In this study, geochemical analyses were performed on a C. concholepas shell with a subdaily time-resolution. Concurrently, high-time resolution information on growth conditions were acquired during the experimental growth of the animals using a highly precise timescale provided by repeated calcein staining. In situ geochemical measurements show that $\mathrm{Sr}$ variations in the shell are not sufficiently important to be interpreted in terms of environmental parameter changes. The very-low Mg content found in the $C$. concholepas calcite layer, measured by LA-ICPMS, most probably indicates a strong physiological control on $\mathrm{Mg}$ incorporation into the shell. In detail, this control appears partly influenced by water temperature when there is daylight. No relation between $\mathrm{Mg}$ concentration, growth rate and water temperature is observed at the daily ( $24 \mathrm{~h}$ ) scale. Instead, distinct processes, both in terms of $\mathrm{Mg}$ incorporation into the shell and shell formation, are at work at a nyctemeral rhythm. During the night, thin matrix-rich increments are formed and Mg intake into the shell carbonate is less important than during the day. This suggests a strong metabolic control that might be related to the increased demand of energy of the $C$. concholepas during the night, at a time when these animals are the most active. This metabolic influence is probably reduced during the day and leaves the temperature impact on $\mathrm{Mg}$ incorporation into the shell more apparent. Clearly, this study shows that $\mathrm{Mg}$ variations in the calcite layer of $\mathrm{C}$. concholepas shells cannot be directly used as a proxy of SST changes without a strong optical control and characterization of the growth increments in which analyses are made.

This is the first time that such differences between day and night shell formation and shell composition are found. The complexity of these metabolic processes (yet to be fully understood) should not be forgotten when $\mathrm{Mg}$ variations within mollusk shells are investigated with the aim to reconstruct paleo-SST. These processes might account for the inconsistencies reported in the literature regarding the use of $\mathrm{Mg}$ as a paleo-SST proxy in other mollusk species.

Further work is needed to better understand the nyctemeral differences observed in the C.concholepas shell and to study in more detail the possible metabolic changes observed between day and night periods. To validate the assumption of a 12-h period offormation for both day and night increments, new staining experiments are already planed. In addition, more individuals must be analyzed and C. concholepas grown in natural conditions should be investigated. The nyctemeral metabolic differences could be studied in more detail, for example by measuring respiratory activity changes and/or $\delta^{13} \mathrm{C}$ ratios in the shell.

\section{ACKNOWLEDGMENTS}

We are grateful for the technical assistance on LA-ICP-MS provided by R. Freydier (LMTG, Toulouse) and wish to acknowledge D. Gillikin, A. Lorrain, M. Elliot and A. Immenhauser for having provided their mollusk $\mathrm{Mg} / \mathrm{Ca}$ data. We are also grateful to $\mathrm{E}$. Dufour for her constructive comments. This work would not have been possible without the help from Chilean students (H.E. Padilla; J. Riascos) (Arturo Prat University, lquique and Antofagasta University). We also thank $D$. Sinclair, O. Sherwood and one anonymous referee for their critical reviews.

This work was partly supported by PALEOTROPIQUE (IRD) and the "CONCHAS" project (Programme National d'Etude de la Dynamique du Climat, INSU, France). This study was financed and conducted in the frame of the EU-Project CENSOR (Climate Variability and EI Nino Southern Oscillation: Implications for Natural Resources and Management, Contract 511071) and is CENSOR Publication 0111.

\section{APPENDIX A. SUPPLEMENTARY DATA}

Supplementary data associated with this article can be found, in the online version, at doi:10.1016/j.gca. 2007.07.031. 


\section{REFERENCES}

Anand P., Elderfield H. and Conte M. H. (2003) Calibration of $\mathrm{Mg} / \mathrm{Ca}$ thermometry in planktonic foraminifera from a sediment trap time series. Paleoceanography 18, 1050. doi: 10.1029/ 2002 PA000846.

Ancey M., Bastenaire F. and Tixier R. (1977) Statistical control and optimization of X-ray intensity measurements. J. Phys. D: Appl. Phys. 10, 817-830.

Andreasson F. P. and Schmitz B. (1998) Tropical Atlantic seasonal dynamics in the early middle Eocene from stable oxygen and carbon isotope profiles of mollusk shells. Paleoceanography 13 , 183-192.

Barker S., Cacho I., Benway H. and Tachikawa K. (2005) Planktonic foraminiferal $\mathrm{Mg} / \mathrm{Ca}$ as a proxy for past oceanic temperatures: a methodological overview and data compilation for the Last Glacial Maximum. Quart. Sci. Rev. 24, 821-834.

Bellotto V. R. and Miekeley N. (2000) Improvements in calibration procedures for the quantitative determination of trace elements in carbonate material (mussel shells) by laser ablation ICP-MS. Fresenius J. Anal. Chem. 367, 635-640.

Bojar A.-V., Hiden H., Fenninger A. and Neubauer F. (2004) Middle Miocene seasonal temperature changes in the Styrian basin, Austria, as recorded by the isotopic composition of pectinid and brachiopod shells. Palaeogeogr. Palaeoclimatol. Palaeoecol. 203, 95-105.

Broecker W. S. and Peng T.-H. (1982) Tracers in the Sea. Eldigio Press, New York.

Carré M., Bentaleb I., Bruguier O., Ordinola E., Barrett N. T. and Fontugne M. (2006) Calcification rate influence on trace element concentrations in aragonitic bivalve shells: evidences and mechanisms. Geochim. Cosmochim. Acta 70, 4906-4920.

Chauvaud L., Lorrain A., Dunbar R. B., Paulet Y.-M., Thouzeau G., Jean F., Guarini J.-M. and Mucciarone D. (2005) Shell of the Great Scallop Pecten maximus as a high-frequency archive of paleoenvironmental changes. Geochem. Geophys. Geosyst.6, Q08001. doi: 10.1029/2004GC000890.

Corrè ge T. (2006) Sea surface temperature and salinity reconstruction from coral geochemical tracers. Palaeogeogr. Palaeoclimatol. Palaeoecol. 232, 408-428.

Craig C. A., Jarvis K. E. and Clarke L. J. (2000) An assessment of calibration strategies for the quantitative and semi-quantitative analysis of calcium carbonate matrices by laser ablationinductively coupled plasma-mass spectrometry (LA-ICP-MS). J. Anal. Atom. Spectrom. 15, 1001-1008.

Cuif J.-P., Dauphin Y., Doucet J., Salome M. and Susini J. (2003) XANES mapping of organic sulfate in three scleractinian coral skeletons. Geochim. Cosmochim. Acta 67, 75-83.

Cuif J. P. and Dauphin Y. (2005) The environment recording unit in coral skeletons: structural and chemical evidences of a biochemically driven stepping-growth process in coral fibres. Biogeosciences 2, 61-73.

Dauphin Y., Cuif J. P., Doucet J., Salome ' M., Susini J. and Williams C. (2003a) In situ mapping of growth lines in the calcitic prismatic layers of mollusc shells using X-ray absorption near-edge structure (XANES) spectroscopy at the sulphur K-edge. Mar. Biol. 142, 299-304.

Dauphin Y., Guzma 'n N., Denis A., Cuif J.-P. and Ortlieb L. (2003b) Microstructure, nanostructure and composition of the shell of Concholepas concholepas (Gastropoda, Muricidae). Aquat. Living Resour. 16, 95-103.

Dauphin Y., Cuif J.-P., Salome C. and Susini J. (2005) Speciation and distribution of sulfur in a mollusk shell as revealed by in situ maps using $\mathrm{X}$-ray absorption near-edge structure (XANES) spectroscopy at the SK-edge. Am. Miner. 90, 17481758.
Elderfield H. and Ganssen G. (2000) Past temperature and $\quad d^{18} \mathrm{O}$ of surface ocean waters inferred from foraminiferal $\mathrm{Mg} / \mathrm{Ca}$ ratios. Nature 405, 442-445.

Epplé V. M. (2004) High-resolution climate reconstruction for the Holocene based on growth chronologies of the bivalve Artica islandica from the North Sea. Ph.D. thesis, University of Bremen.

Epstein S., Buchsbaum R., Lowenstam H. A. and Urey H. C. (1953) Revised carbonate-water isotopic temperature scale. Geol. Soc. Am. Bull. 64, 1315-1326.

Epstein S. and Mayeda T. (1953) Variation of ${ }^{18} \mathrm{O}$ content of waters from natural sources. Geochim. Cosmochim. Acta 4, 213224.

Fallon S. J., McCulloch M. T. and Alibert C. (2003) Examining water temperature proxies in Porites corals from the Great Barrier Reef: a cross-shelf comparison. Coral Reefs 22, 389404.

Fallon S. J., McCulloch M. T., Woesik R. v. and Sinclair D. J. (1999) Corals at their latitudinal limits: laser ablation trace element systematics in Porites from Shirigai Bay, Japan. Earth Planet. Sci. Lett. 172, 221-238.

Fallon S. J., White J. C. and McCulloch M. T. (2002) Porites corals as recorders of mining and environmental impacts: Misima Island, Papua New Guinea. Geochim. Cosmochim. Acta 66, 4562.

Foster P. and Cravo A. (2003) Minor elements and trace metals in the shell of marine gastropods from a shore in tropical East Africa. Water Air Soil Pollut. 145, 53-65.

Freitas P., Clarke L. J., Kennedy H., Richardson C. and Abrantes F. (2005) $\mathrm{Mg} / \mathrm{Ca}, \mathrm{Sr} / \mathrm{Ca}$, and stable-isotope $\left(\mathrm{d}^{18} \mathrm{O}\right.$ and $\left.\mathrm{d}^{13} \mathrm{C}\right)$ ratio profiles from the fan mussel Pinna nobilis: seasonal records and temperature relationships. Geochem. Geophys. Geosyst. 6, Q04D14. doi: $10.1029 / 2004 G C 000872$.

Fuge R. F., Palmer T. J., Pearce N. J. G. and Perkins W. T. (1993) Minor and trace element chemistry of modern shells: a laser ablation inductively coupled plasma mass spectrometry study. Appl. Geochem. 2, 111-116.

Geertsen C., Briand A., Chartier F., Lacour J.-L., Patrick M., Sjo" ström S. and Mermet J.-M. (1994) Comparison between infrared and ultraviolet laser ablation at atmospheric pressure-implications for solid sampling inductively coupled plasma spectrometry. J. Anal. Atom. Spectrom. 9, 17-22.

Geist J., Auerswald K. and Boom A. (2005) Stable carbon isotopes in freshwater mussel shells: environmental record or marker for metabolic activity? Geochim. Cosmochim. Acta 69, 3545-3554.

Gillikin D. P. (2005) Geochemistry of marine bivalve shells: the potential for paleoenvironmental reconstruction. Ph.D. thesis, Vrije Universiteit Brussel.

Gillikin D. P., Lorrain A., Navez J., Taylor J. W., Andre ' L., Keppens E., Baeyens W. and Dehairs F. (2005) Strong biological controls on $\mathrm{Sr} / \mathrm{Ca}$ ratios in aragonitic marine bivalve shells. Geochem. Geophys. Geosyst. 6, Q05009. doi: 10.1029/ 2004GC000874.

Goodwin D. H., Scho"ne B. R. and Dettman D. L. (2003) Resolution and fidelity of oxygen isotopes as paleotemperature proxies in bivalve mollusk shells: models and observations. Palaios 18, 110-125.

Govindaraju K. (1994) Compilation of working values and sample description for 383 geostandards. Geostandard Newslett. 18, 1158.

Guillong M. and Gu"nther D. (2002) Effect of particle size distribution on ICP-induced elemental fractionation in laser ablation-inductively coupled plasma-mass spectrometry. J. Anal. Atom. Spectrom. 17, 831-837. 
Gü nther D., Longerich H. P., Forsythe L. and Jackson S. E. (1995) Laser ablation microprobe-inductively coupled plasma-mass spectrometry. Am. Lab. 9, 24-29.

Gü nther D., Jackson S. E. and Longerich H. P. (1999) Laser ablation and arc/spark solid sample introduction into inductively coupled plasma mass spectrometers. Spectrochim. Acta 54, 381-409.

Guzmá n N. (2004) Validation d'une approche scle'roclimatologique sur la côte du Chili et du Pérou par l'analyse microstructurale et biogéochimique des coquilles du gasteropode Concholepas concholepas [Bruguière, 1789]. Ph.D. thesis, Universite' de Paris-Sud.

Guzmán n N., Ball A., Cuif J.-P., Dauphin Y., Denis A. and Ortlieb L. (2007) Sub-daily growth patterns and organo-mineral nanostructure of the growth layers in the calcitic prisms of the shell of Concholepas concholepasBruguière, 1789 (Gastropoda, Muricidae). Microsc. Microanal. 13, 397-403.

Haase-Schramm A., Bo "hm F., Eisenhauer A., Dullo W.-C., Joachimski M. M., Hansen B. and Reitner J. (2003) Sr/Ca ratios and oxygen isotopes from sclerosponges: temperature history of the Caribbean mixed layer and thermocline during the Little Ice Age. Paleoceanography 18, 1073-1088.

Hendry J. P., Perkins W. T. and Bane T. (2001) Short-term environmental change in a Jurassic lagoon deduced from geochemical trends in aragonite bivalve shells. Geol. Soc. Am. Bull. 113, 790-798.

Horng-Sheng M. and Grossman E. L. (1994) Late Pennsylvanian seasonality reflected in the ${ }^{18} \mathrm{O}$ and elemental composition of a brachiopod shell. Geology 22, 661-664.

Immenhauser A., Nagler T. F., Steuber T. and Hippler D. (2005) A critical assessment of mollusk ${ }^{18} \mathrm{O} /{ }^{16} \mathrm{O}, \mathrm{Mg} / \mathrm{Ca}$, and ${ }^{44} \mathrm{Ca} /{ }^{40} \mathrm{Ca}$ ratios as proxies for Cretaceous seawater temperature seasonality. Palaeogeogr. Palaeoclimatol. Palaeoecol. 215, 221-237.

Jones D. S. (1983) Sclerochronology: reading the record of the molluscan shell. Am. Sci. 71, 384-391.

Kilbourne K. H., Quinn T. M. and Taylor F. W. (2004) A fossil coral perspective on western tropical Pacific climate $\sim 350 \mathrm{ka}$. Paleoceanography 19, PA1019. doi: 10.1029/2003PA000944.

Klein R. T., Lohmann K. C. and Kennedy G. L. (1997) Elemental and isotopic proxies of paleotemperature and paleosalinity: climate reconstruction of the marginal northeast Pacific ca. 80 ka. Geology 25, 363-366.

Klein R. T., Lohmann K. C. and Thayer C. W. (1996) Bivalve skeletons record sea-surface temperature and $\mathrm{d}^{18} \mathrm{O}$ via $\mathrm{Mg} / \mathrm{Ca}$ and ${ }^{18} \mathrm{O} /{ }^{16} \mathrm{O}$ ratios. Geology $24,415-418$.

Krantz D. E., Williams D. F. and Jones D. S. (1987) Ecological and paleoenvironmental information using stable isotope profiles from living and fossil mollusks. Palaeogeogr. Palaeoclimatol. Palaeoecol. 58, 249-266.

Kuhn H.-R. and Gu "nther D. (2004) Laser ablation-ICP-MS: particle size dependent elemental composition studies on filtercollected and online measured aerosols from glass. J. Anal. Atom. Spectrom. 19, 1158-1164.

Labonne M. and Hillaire-Marcel C. (2000) Geochemical gradients within modern and fossil shells of Concholepas concholepas from northern Chile: an insight into U-Th systematics and diagenetic/authigenic isotopic imprints in mollusk shells. Geochim. Cosmochim. Acta 64, 1523-1534.

Lazareth C. E., van der Putten E., Andre ' L. and Dehairs F. (2003) High-resolution trace element profiles in shells of the mangrove bivalve Isognomon ephippiuma record of environmental spatiotemporal variations? Estuar. Coast. Shelf Sci. 57, 1103-1114.

Lea D. W., Mashiotta T. A. and Spero H. J. (1999) Controls on magnesium and strontium uptake in planktonic foraminifera determined by live culturing. Geochim. Cosmochim. Acta 63, 2369-2379.
Lear C. H., Rosenthal Y. and Slowey N. (2002) Benthic foraminiferal $\mathrm{Mg} / \mathrm{Ca}$-paleothermometry: a revised core-top calibration. Geochim. Cosmochim. Acta 66, 3375-3387.

Lee X., Hu R., Brand U., Zhou H., Liu X., Yuan H., Yan C. and Cheng $H$. (2004) Ontogenetic trace element distribution in brachiopod shells: an indicator of original seawater chemistry. Chem. Geol. 209, 49-65.

Longerich H. P., Gu "nther D. and Jackson S. E. (1996) Elemental fractionation in laser ablation inductively coupled plasma mass spectrometry. Fresenius J. Anal. Chem. 355, 538-542.

Lorens R. B. and Bender M. L. (1977) Physiological exclusion of magnesium from Mytilus edulis calcite. Nature 269, 793-794.

Lorens R. B. and Bender M. L. (1980) The impact of solution chemistry on Mytilus edulis calcite and aragonite. Geochim. Cosmochim. Acta 44, 1265-1278.

Lorrain A., Gillikin D. P., Paulet Y.-M., Chauvaud L., Le Mercier A., Navez J. and Andre L. (2005) Strong kinetic effects on Sr/ Ca ratios in the calcitic bivalve Pecten maximus. Geology 33, 965-968.

Lorrain A., Paulet Y.-M., Chauvaud L., Dunbar R., Mucciarone D. and Fontugne M. (2004) $d^{13} C$ variation in scallop shells: Increasing metabolic carbon contribution with body size? Geochim. Cosmochim. Acta 68, 3509-3519.

Lutz R. A. and Rhoads D. C. (1980) Growth patterns within the molluskan shell, an overview. In Skeletal Growth of Aquatic Organisms: Biological Records of Environmental Change, vol. 1 (eds. D. C. Rhoads and R. A. Lutz) . Plenum Press, New York, pp. 203-255.

Masuda F. and Hirano M. (1980) Chemical composition of some modern pelecypod shells. Sci. Rep. Inst. Geosci. Univ. Tsukuba B 1, 163-177.

McCulloch M. T., Gagan M. K., Mortimer G. E., Chivas A. R. and Isdale P. J. (1994) A high-resolution $\mathrm{Sr} / \mathrm{Ca}$ and $\quad \mathrm{d}^{18} \mathrm{O}$ coral record from the Great Barrier Reef, Australia, and the 19821983 El Niñ o. Geochim. Cosmochim. Acta 58, 2747-2754.

Morales-Nin B. (1987) Ultrastructure of the organic and inorganic constituents of the otoliths of the sea bass. In Age and Growth of Fish (eds. R. C. Summerfelt and G. E. Hall) . lowa State University Press, lowa, pp. 331-343.

Mucci A. (1987) Influence of temperature on the composition of magnesian calcite overgrowths precipitated from seawater. Geochim. Cosmochim. Acta 51, 1977-1984.

Norman M. D., Pearson N. J., Sharma A. and Griffin W. L. (1996) Quantitative analysis of trace elements in geological materials by laser ablation ICPMS: instrumental operating conditions and calibration values of NIST glasses. Geostandard Newslett. 20, 247-261.

Nürnberg D., Bijma J. and Hemleben C. (1996) Assessing the reliability of magnesium in foraminiferal calcite as a proxy for water mass temperatures. Geochim. Cosmochim. Acta 60, 803814.

Owen R., Kennedy H. and Richardson C. (2002) Experimental investigation into partitioning of stable isotopes between scallop (Pecten maximus) shell calcite and sea water. Palaeogeogr. Palaeoclimatol. Palaeoecol. 185, 163-174.

Palmer R. A. (1983) Relative cost of producing skeletal organic matrix versus calcification: evidence from marine gastropods. Mar. Biol. 75, 287-292.

Palmer R. A. (1992) Calcification in marine mollusks: how costly is it? Proc. Natl. Acad. Sci. USA 89, 1379-1382.

Panella G. (1980) Growth patterns of fish sagittae. In Skeletal Growth of Aquatic Organisms: Biological Records of Environmental Change (eds. D. C. Rhoads and R. A. Lutz) . Plenum Press, New York, pp. 133-167.

Pearce N. J. G., Perkins W. T. and Fuge R. (1992) Developments in the quantitative and semiquantitative determination of trace 
elements in carbonates by laser ablation inductively coupled plasma mass spectrometry. J. Anal. Atom. Spectrom. 7, 595599.

Pearce N. J. G., Perkins W. T., Westgate J. A., Gorton M. P., Jackson S. E., Neal C. R. and Chenery S. P. (1997) A compilation of new and published major and trace element data for NIST SRM 610 and NIST SRM 612 glass reference materials. Geostandard Newslett. 21, 115-144.

Perkins W. T., Fuge R. and Pearce N. J. G. (1991) Quantitative analysis of trace elements in carbonates using laser ablation inductively coupled plasma mass spectrometry. J. Anal. Atom. Spectrom. 6, 445-449.

Pirker J. G. and Schiel D. R. (1993) Tetracycline as a fluorescent shell-marker in the abalone Haliotis iris . Mar. Biol. 116, 81-86.

Poitrasson F., Chenery S. and Bland D. J. (1996) Contrasted monazite hydrothermal alteration mechanisms and their geochemical implications. Earth Planet. Sci. Lett. 145, 79-96.

Poitrasson F. (2001) Principe et utilisation du LA-ICP-MS en Sciences de la Terre. Bull. Liais. Soc. Fr. Mine 'r. Cristal. 13, 924.

Price G. D. and Pearce N. J. G. (1997) Biomonitoring of pollution by Cerastoderma edule from the British Isles: a laser ablation ICP-MS study. Mar. Pollut. Bull. 34, 1025-1031.

Quinn T. M. and Sampson D. E. (2002) A multiproxy approach to reconstructing sea surface conditions using coral skeleton geochemistry. Paleoceanography 17, 1062-1072.

Quinn T. M. and Sampson D. S. (2003) Ame 'dée Coral Elemental Ratios and Isotope Data. IGBP PAGES/World Data Center for Paleoclimatology. Data Contribution Series \#2003-073. NOAA/NGDC Paleoclimatology Program, Boulder CO, USA.

Raith A., Perkins W. T., Pearce N. J. G. and Jeffries T. E. (1996) Environmental monitoring on shellfish using UV laser ablation ICP-MS. Fresenius J. Anal. Chem. 355, 789-792.

Richardson C. A. (2001) Molluscs as archives of environmental changes. In Oceanography and Marine Biology: An Annual Review (eds. R. N. Gibson, M. Barnes and R. J. A. Atkinson) Taylor and Francis, London, pp. 103-164.

Richardson C. A., Peharda M., Kennedy H., Kennedy P. and Onofri V. (2004) Age, growth rate and season of recruitment of Pinna nobilis $(\mathrm{L})$ in the Croatian Adriatic determined from $\mathrm{Mg}: \mathrm{Ca}$ and Sr:Ca shell profiles. J. Exp. Mar. Biol. Ecol. 299, 1-16.

Rosenberg G. D. and Hughes W. W. (1991) A metabolic model for the determination of shell composition in the bivalve mollusc, Mytilus edulis. Lethaia 24, 83-96.

Rosenberg G. D., Hughes W. W. and Trachuck R. D. (1989) Shell form and metabolic gradients in the mantle of Mytilus edulis. Hydrobiologica 22, 343-344.

Rosenberg G. D., Hughes W. W., Parker D. L. and Ray B. D. (2001) The geometry of bivalve shell chemistry and mantle metabolism. Am. Malacol. Bull. 16, 251-261.

Rosenheim B. E., Swart P. K. and Thorrold S. R. (2005) Minor and trace elements in sclerosponge Ceratoporella nicholsoni: biogenic aragonite near the inorganic endmember? Palaeogeogr. Palaeoclimatol. Palaeoecol. 228, 109-129.

Rosenheim B. E., Swart P. K., Thorrold S. R., Willenz P., Berry L. and Latkoczy C. (2004) High-resolution Sr/Ca records in sclerosponges calibrated to temperature in situ. Geology 32, 145-148.

Runnalls L. A. and Coleman M. L. (2003) Record of natural and anthropogenic changes in reef environments (Barbados West Indies) using laser ablation ICP-MS and sclerochronology on coral cores. Coral Reefs 22, 416-426.

Schmidt M. W., Vautravers M. J. and Spero H. J. (2006) Western Caribbean sea surface temperatures during the late Quaternary-art. no. Q02P10. Geochem. Geophys. Geosyst.7, Q02P10. doi: 10.1029/2005GC000957.
Schöne B. R., Freyre Castro A. D., Fiebig J., Houk S. D., Oschmann W. and Kroncke I. (2004) Sea surface water temperatures over the period 1884-1983 reconstructed from oxygen isotope ratios of a bivalve mollusk shell (Arctica islandica, southern North Sea). Palaeogeogr. Palaeoclimatol. Palaeoecol. 212, 215-232.

Schöne B. R., Dunca E., Fiebig J. and Pfeiffer M. (2005) Mutvei's solution: an ideal agent for resolving microgrowth structures of biogenic carbonates. Palaeogeogr. Palaeoclimatol. Palaeoecol. 228, 149-166.

Shepherd S. A., Avalos-Borja M. and Quintanilla M. O. (1995) Toward a chronology of Haliotis fulgens, with a review of abalone shell microstructure. Mar. Freshwater Res. 46, 607-615.

Sinclair D. J., Kinsley L. P. J. and McCulloch M. T. (1998) High resolution analysis of trace elements in corals by laser ablation ICP-MS. Geochim. Cosmochim. Acta 62, 1889-1901.

Stecher H. A., Krantz D. E., Lord, III, C. J., Luther, III, G. W. and Bock K. W. (1996) Profiles of strontium and barium in Mercenaria mercenaria and Spisula solidissima shells. Geochim. Cosmochim. Acta 60, 3445-3456.

Steuber T. and Rauch M. (2005) Evolution of the $\mathrm{Mg} / \mathrm{Ca}$ ratio of Cretaceous seawater: implications from the composition of biological low-Mg calcite. Mar. Geol. 217, 199-213.

Takesue R. K. and van Geen A. (2004) Mg/Ca, Sr/Ca, and stable isotopes in modern and Holocene Protothaca staminea shells from a northern California coastal upwelling region. Geochim. Cosmochim. Acta 68, 3845-3861.

Toland H., Perkins B., Pearce N., Keenan F. and Leng M. J. (2000) A study of sclerochronology by laser ablation ICP-MS. J. Anal. Atom. Spectrom. 15, 9.

Tudhope A. W., Chilcott C. P., McCulloch M. T., Cook E. R., Chappell J., Ellam R. M., Lea D. W., Lough J. M. and Shimmield G. B. (2001) Variability in the El Nin -o-Southern Oscillation through a glacial-interglacial cycle. Science 291, 1511-1517.

van der Putten E., Dehairs F., Andre ' L. and Baeyens W. (1999) Quantitative in situ microanalysis of minor and trace elements in biogenic calcite using infrared laser ablation-inductively coupled plasma mass spectrometry: a critical evaluation. Anal. Chim. Acta 378, 261-272.

van der Putten E., Dehairs F., Keppens E. and Baeyens W. (2000) High resolution distribution of trace elements in the calcite shell layer of modern Mytilus edulis: environmental and biological controls. Geochim. Cosmochim. Acta 64, 997-1011.

Weidman C. R., Jones G. A. and Lohman K. C. (1994) The longlived mollusk Arctica islandica: a new paleoceanographic tool for the reconstruction of bottom temperatures for the continental shelves of the Northern North-Atlantic ocean. J. Geophys. Res. Oceans 99, 18305-18314.

Wilbur K. M. and Saleuddin A. S. M. (1983) Shell Formation. In The Mollusca, Physiology, Part 1 (eds. A. S. M. Saleuddin and K. M. Wilbur) . Academic Press, New York, pp. 235-287.

Wright P. J., Panfili J., Morales-Nin B. and Greffen A. J. (2002) Types of calcified structures. A. Otoliths. In: Manual of fish sclerochronology(eds. J. Panfili, H. De Pontual, H. Troadec and P. J. Wright), Ifremer-IRD coed., pp. 31-57.

Yoshinaga J., Nakama A., Morita M. and Edmonds J. S. (2000) Fish otolith reference material for quality assurance of chemical analyses. Mar. Chem. 69, 91-97.

Yu K.-F., Zhao J.-X., Wei G.-J., Cheng X.-R. and Wang P.-X. (2005) Mid-late Holocene monsoon climate retrieved from seasonal $\mathrm{Sr} / \mathrm{Ca}$ and $\mathrm{d}^{18} \mathrm{O}$ records of Porites lutea corals at Leizhou Peninsula, northern coast of South China Sea. Global Planet. Change 47, 301-316. 

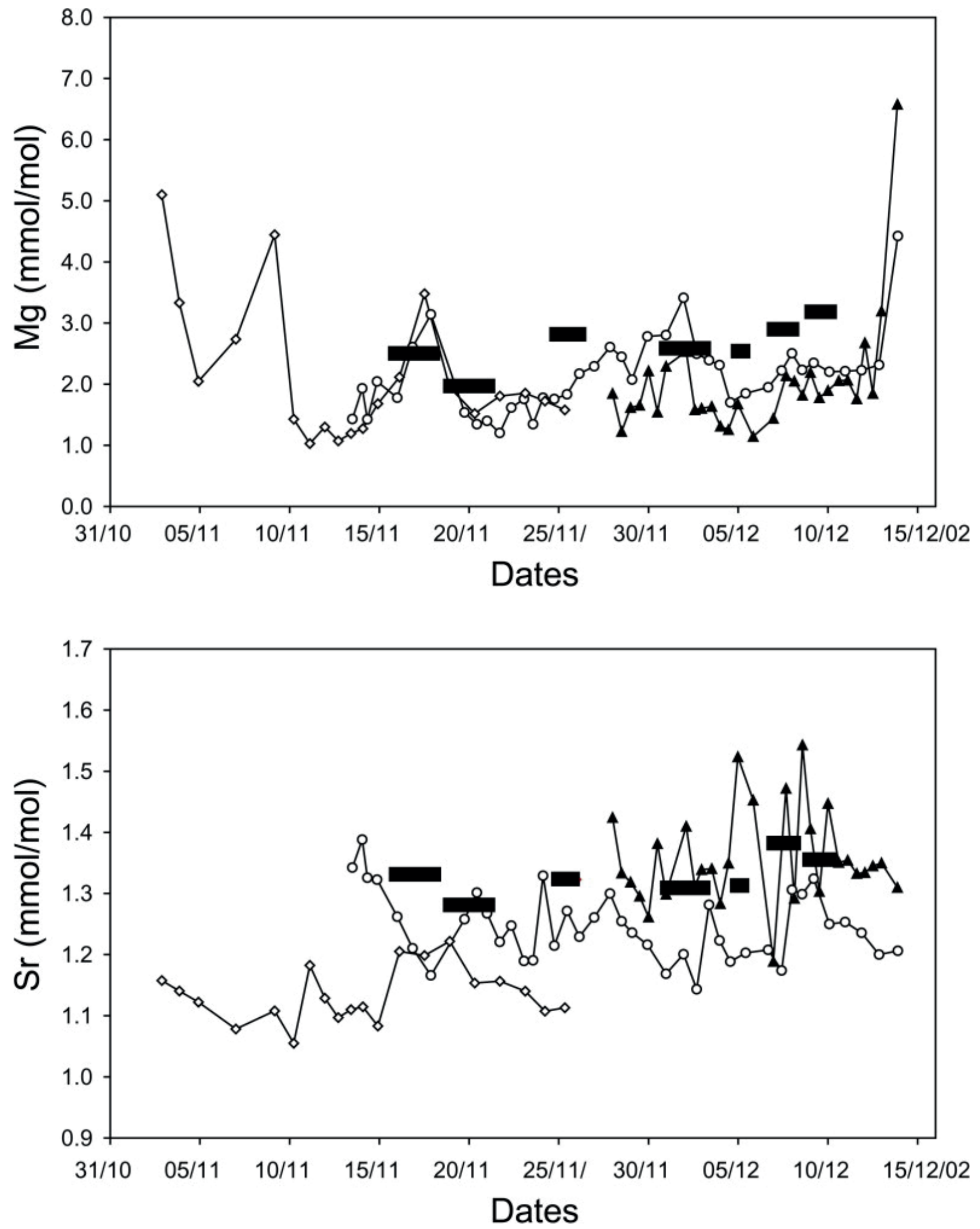

Supplementary Figure 1. Electronic annex 1: Comparison of LASER ICP-MS profiles and standard liquid ICP-MS analyses done on micromilled samples from a third section of the C. concholepas shell studied. Standard liquid ICP-MS are represented as a bar which represents the amount of time of shell growth averaged. 


\begin{tabular}{|c|c|c|c|}
\hline $\mathrm{Mg} / \mathrm{Ca}(\mathrm{mmol} / \mathrm{mol})$ & $\begin{array}{c}\mathrm{Mg} / \mathrm{Ca}(\mathrm{mmol} / \mathrm{mol}) \\
\text { suite }\end{array}$ & $\begin{array}{c}\mathrm{Mg} / \mathrm{Ca}(\mathrm{mmol} / \mathrm{mol}) \\
\text { suite }\end{array}$ & $\underset{\text { suite }}{\mathrm{Mg} / \mathrm{Ca}(\mathrm{mmol} / \mathrm{mol})}$ \\
\hline 23.15 & 23.19 & 31.52 & 23.79 \\
\hline 24.86 & 22.08 & 30.37 & 24.42 \\
\hline 24.27 & 22.30 & 31.95 & 24.21 \\
\hline 23.90 & 23.35 & 31.82 & 24.37 \\
\hline 24.08 & 23.62 & 31.92 & 23.70 \\
\hline 23.76 & 24.11 & 31.73 & 24.77 \\
\hline 23.39 & 23.41 & 32.00 & 25.01 \\
\hline 23.03 & 25.03 & 31.68 & 24.83 \\
\hline 23.86 & 24.83 & 31.96 & 26.33 \\
\hline 23.15 & 24.35 & 33.75 & 24.69 \\
\hline 21.92 & 23.58 & 32.84 & 26.10 \\
\hline 21.70 & 22.78 & 33.68 & 27.41 \\
\hline 21.99 & 21.89 & 33.77 & 29.84 \\
\hline 22.35 & 23.02 & 30.59 & 29.49 \\
\hline 21.97 & 23.77 & 29.08 & 30.30 \\
\hline 22.22 & 22.98 & 29.33 & 30.64 \\
\hline 22.61 & 23.28 & 28.98 & 31.18 \\
\hline 21.12 & 23.95 & 29.20 & 29.25 \\
\hline 20.59 & 23.35 & 29.56 & 29.61 \\
\hline 20.42 & 23.71 & 29.19 & 29.75 \\
\hline 20.55 & 22.99 & 29.55 & 28.46 \\
\hline 22.45 & 24.00 & 30.45 & 29.73 \\
\hline 22.62 & 22.90 & 31.17 & 29.36 \\
\hline 22.31 & 24.39 & 29.14 & 28.73 \\
\hline 23.26 & 24.18 & 27.93 & 28.52 \\
\hline 22.93 & 23.35 & 25.90 & 28.24 \\
\hline 22.26 & 23.77 & 25.92 & 27.92 \\
\hline 23.00 & 24.90 & 25.76 & 26.89 \\
\hline 21.59 & 25.21 & 25.30 & 26.51 \\
\hline 22.04 & 23.36 & 25.87 & 27.06 \\
\hline 22.15 & 23.45 & 24.75 & 26.52 \\
\hline 20.90 & 24.79 & 24.49 & 24.86 \\
\hline 20.95 & 25.67 & 24.77 & 24.12 \\
\hline 19.89 & 23.21 & 24.80 & 23.56 \\
\hline 19.44 & 23.32 & 24.56 & 23.78 \\
\hline 19.72 & 22.62 & 24.37 & 24.33 \\
\hline 20.17 & 22.21 & 24.12 & 24.76 \\
\hline 19.70 & 23.09 & 25.01 & 25.40 \\
\hline 19.55 & 20.98 & 25.97 & 25.29 \\
\hline 19.11 & 20.20 & 26.36 & 24.85 \\
\hline 19.11 & 22.25 & 26.75 & 26.72 \\
\hline 19.92 & 21.58 & 27.10 & 27.37 \\
\hline 19.60 & 21.99 & 26.79 & 31.93 \\
\hline 19.56 & 20.18 & 27.47 & 28.63 \\
\hline 21.11 & 20.48 & 27.69 & 28.81 \\
\hline 20.44 & 20.04 & 27.60 & 29.58 \\
\hline 19.98 & 19.25 & 28.02 & 30.35 \\
\hline 21.02 & 20.50 & 28.82 & 31.31 \\
\hline 20.67 & 20.56 & 28.31 & 33.11 \\
\hline 21.50 & 20.95 & 28.85 & 33.01 \\
\hline 21.85 & 20.96 & 29.18 & 31.34 \\
\hline 20.57 & 21.45 & 29.40 & 28.91 \\
\hline 20.23 & 20.86 & 30.50 & 24.39 \\
\hline 20.89 & 20.54 & 30.59 & 23.68 \\
\hline 21.70 & 21.76 & 29.97 & 24.93 \\
\hline 21.16 & 21.09 & 29.09 & 32.92 \\
\hline 21.54 & 21.73 & 28.17 & 29.43 \\
\hline 21.83 & 22.16 & 29.21 & 30.24 \\
\hline 21.55 & 21.79 & 29.42 & 31.72 \\
\hline 21.87 & 21.75 & 29.10 & 30.74 \\
\hline 22.16 & 23.47 & 28.49 & 32.02 \\
\hline 21.49 & 23.83 & 28.69 & 31.32 \\
\hline 21.71 & 23.35 & 29.92 & 32.48 \\
\hline 21.80 & 23.11 & 29.98 & 32.01 \\
\hline 23.32 & 23.60 & 29.80 & 32.09 \\
\hline 22.57 & 24.17 & 31.42 & 31.50 \\
\hline 23.63 & 24.50 & 30.78 & 31.72 \\
\hline 23.76 & 25.09 & 29.67 & 32.04 \\
\hline 24.25 & 24.72 & 27.75 & 33.55 \\
\hline 23.18 & 26.47 & 27.87 & 34.89 \\
\hline 22.76 & 23.81 & 28.37 & 36.21 \\
\hline 22.27 & 26.31 & 27.84 & 36.49 \\
\hline \multirow{5}{*}{22.25} & 27.97 & 26.33 & 37.29 \\
\hline & 28.64 & 26.16 & 38.17 \\
\hline & 29.72 & 23.94 & 36.75 \\
\hline & & & 38.92 \\
\hline & & & 40.68 \\
\hline
\end{tabular}

Supplementary data. Electronic annex 2: Isognomon ephippium Mg/Ca shell ratios. Data obtained by LA-ICP-MS at the Royal Museum for Central Africa, Tervüren, Belgium. This work was supported by a Post Doctoral Grant to C.E. Lazareth under the European Union Training and Mobility of Researchers (TMR) Program, Contract FMBICT983440 and by EC-INCO research project IC18-CT96-0065 and FWO Flanders Contract. 